\title{
Seismic Behavior of the Removable Links in Eccentrically Braced Frames with Semirigid Connections
}

\author{
Qiang Shi, ${ }^{1,2}$ Shilin Yan $\mathbb{D}^{1},{ }^{1}$ Xinwu Wang $\mathbb{D}^{2},{ }^{2}$ Haisu Sun, ${ }^{2}$ and Yan Zhao ${ }^{2}$ \\ ${ }^{1}$ Hubei Key Laboratory of Theory and Application of Advanced Materials Mechanics, Wuhan University of Technology, \\ Wuhan, China \\ ${ }^{2}$ Henan International Joint Laboratory of New Civil Engineering Structure, Luoyang Institute of Science and Technology, \\ Luoyang, China \\ Correspondence should be addressed to Shilin Yan; yanshl507@126.com and Xinwu Wang; wxw197100@sina.com
}

Received 12 August 2019; Revised 29 March 2020; Accepted 3 April 2020; Published 25 April 2020

Academic Editor: Jiang Jin

Copyright (c) 2020 Qiang Shi et al. This is an open access article distributed under the Creative Commons Attribution License, which permits unrestricted use, distribution, and reproduction in any medium, provided the original work is properly cited.

\begin{abstract}
Eccentrically braced frames (EBFs) have good elastic stiffness, while semirigid joints can provide greater ductility and make all components easy to fabricate. With application of semirigid connections to EBFs, a seismic structure can be formed. After earthquake, damaged components can be easily replaced, and repair costs and maintenance time can be reduced. In order to study the seismic performance of this type of structure, four single-story plane specimens were tested under low-cycle cyclic loads. Also, a total of $7 \mathrm{EBF}$ models were investigated through three-dimensional, nonlinear finite element analysis. Good agreement is achieved between the simulation and experimental results. The results show that the failure modes of the EBFs with semirigid connections are the fracture at link end plate connection, and no obvious buckling deformation and cracks occur in the other components. The EBFs with semirigid connections exhibit good inelastic rotation ability, and the inelastic rotation of all specimens and models exceeds the limit of 2016 AISC specification. Due to the slip between members, the hysteretic curves of those new structures show different degrees of pinching phenomenon and it becomes more obvious with the increase of the length of links. By analyzing the strain of the bolts, it is found that the bolt strains of the joints of link-to-beam are the highest, while the bolt strains of the joints of beam-to-column and column-to-brace are smaller. This structure system shows higher energy dissipation capacity and good economic benefits.
\end{abstract}

\section{Introduction}

Semirigid joints increase ductility and energy dissipation of frame structures, but the structural stiffness is low and lateral displacement is large. The study of the removable links in eccentrically braced frames (EBFs) with semirigid connections is of paramount importance because from one side the idea of removable links allows substituting the element after the occurrence of an earthquake. From another side, the use of semirigid connections allows for designing lighter structures. However, semirigid connections can affect the overall dissipative capacity of the link. $\mathrm{Hu}$ [1] fully considered the geometric nonlinearity, material nonlinearity, residual stress, initial defects, semirigid joints, and other factors, and performance-based plastic design methods of various EBFs are derived. Shi et al. [2] completed the low-cycle cyclic loading tests of several EBFs with semirigid connections, and the bearing capacity and deformation characteristics and failure modes of the frames were studied. This topic has also been faced by the recently accomplished EQUALJOINTS Plus Dissemination project, where many EBFs structures have been modeled and analyzed accounting for prequalified semirigid connections. The results of this project, mainly for what regards EBFs, are reported in [3]. EBFs can improve the lateral stiffness of the structure and have a certain ductility and energy dissipation capacity. The structure is formed by combining eccentric bracing frames with semirigid connections. During minor seismic events, this new type of structure can ensure that the drift of the frame decreases significantly; thus, it will meet the functional requirements. In the event of a rare overload that might 
occur during a major earthquake, the link yields first to protect the brace from buckling. At the same time, all members are connected by bolts, which reduces the welding procedure in the construction site, and the postearthquake repair is simple, cost-effective, and efficient.

Joints play a key role in frame structure. Codes AISC [4], EC3 [5], and GB50017 [6] usually divide joints into rigid joints, articulated joints, and semirigid joints. Welded joints are usually used in traditional buildings, that is, rigid joints. During strong earthquake in the 1994 Northridge and 1995 Kobe, a large number of brittle cracks occurred in the welds of beam-to-column rigid joints, which caused serious damage to buildings. Since the 1960s, many scholars have done a lot of experiment research on semirigid beamto-column joints with high-strength bolts. Nethercot [7-9] collected the experimental data of all bolts and welded joints; the energy dissipation characteristics of semirigid joints were summarized, and the corresponding database was established; for each joint, several calculation formulas were put forward. At the same time, some suggestions on the application of these formulas were given to the designers. Elnashai et al. $[10,11]$ studied the influence of the stiffness and bearing capacity of joints on the stiffness and bearing capacity of the whole frame structure through experiments, the vibration period of semirigid frame was analyzed, and the conclusion that semirigid joint can effectively reduce the seismic effect was obtained; and the drift is lower than that of rigid frame when the acceleration reaches the maximum value. Semirigid joints connect beams and columns as a whole mainly through highstrength bolts and connectors (angle steel, short T-section steel, end plate, etc.). Therefore, their mechanical properties are between ideal rigid joints and ideal hinged joints. It can withstand a certain amount of bending moment and rotation capacity and has good ductility and energy dissipation performance, but its stiffness is low and the structure is flexible. When the lateral stiffness is used as the design control condition, this results in overdesigned members and increased overall costs. EBFs structure system is an optimal seismic structure scheme in earthquake-prone areas. EBFs refer to the structure system with at least one end of the brace connected to the beam, the bracing axis deviates from the intersection of the beam and column, and the link formed at the end or in the middle of the beam. EBFs have the advantages of high strength, high stiffness of centrally supported frame, and high energy dissipation capacity of pure frame. Rides et al. [12-15] put forward the concept of beam element model of inelastic characteristics of link through experimental research. Based on the capacity design criterion, the overstrength factor of link under earthquake action is studied. The mechanical properties of intermediate link and long link are evaluated. Through analysis, the major factors affecting the performance of the two kinds of links are obtained. Many experimental tests were performed in the past on removable links [16-26]. For instance, Chesoan et al. [16] carried out experimental research on full-scale dual eccentrically braced structure. Experiment test showed an excellent performance at the SLS and ULS earthquakes. Small permanent deformations were recorded for seismic intensity levels corresponding to SLS/ULS, which are within the erection tolerance limits. Mansour et al. [21] tested two different replaceable link types with alternate section profiles, connection configurations, welding details, and intermediate stiffener spacings. The links exhibited a very good ductile behavior, developing stable and repeatable yielding. Bozkurt et al. [26] proposed a detachable replaceable link detail, which is based on splicing the link at its mid-length. Performance of this proposed replaceable link is studied by conducting six nearly full-scale EBF tests under quasi-static cyclic loading. The test results revealed that the inelastic rotation capacity of the detachable replaceable links exceeds the requirements of the AISC Seismic Provisions for Structural Steel Buildings. No failures are observed in the end-plated mid-splice connections demonstrating the potential of the proposed details.

At present, in the design of EBFs (such as AISC2016 [4], CSA2009 [27], NZS3404 [28], and GB50011-2010 [29]), all members are joined together by welding. On one hand, this connection mode is not suitable for factory prefabricated and field assembled fabrication buildings. On the other hand, the link is designed to consume seismic energy through obvious plastic deformation under earthquake. In this case, the structure or components may need to be repaired or replaced after earthquake. Then, the bolted connections make repair simple and fast.

In order to overcome the shortcomings of overflexibility of semirigid joint frames and the difficulty of repair, highcost, and time-consuming welded EBFs after earthquake, in this paper, the components of EBFs are bolted together to form a seismic structure, which can reduce the site welding construction and the cost of postearthquake repair. To investigate the inelastic seismic behavior of this system, three EBFs with high-strength bolts are designed in this paper. The links are made of Q235 steel, and the other components are made of Q345 steel with higher yield point.

As a comparison, a welded EBF is designed. The seismic performance and failure mechanism of the EBFs with semirigid connections are studied by quasi-static test, which provides a basis for engineering application.

\section{Experimental Program}

2.1. Test Specimens. The specimens are single-story steel frame structure with a height of 3.6 meters and a span of 6 meters. The specimens are designed in a scale of $1: 2$, and the height of the stories is 1.8 meters and the span is 3 meters. Each component is designed according to GB50011-2010 [23] and GB50017-2017 [6]; the bearing capacity of the test frame is checked with reference to AISC341-16 [4]. The design principles of EBFs are strong columns, strong beams, strong braces, and weak link. As the first yielding member in the structure, the strength of energy dissipation beam should not be too high. Based on the above principles, the dimensions and materials of each component in the specimen are shown in Table 1. EBFs configuration used in this paper is shown in Figure 1. 
TABLe 1: Sections and materials of components.

\begin{tabular}{lcc}
\hline Section & Type & Materials \\
\hline Beam & $\mathrm{H} 250 \times 125 \times 6 \times 9$ & Q345B \\
Column & $\mathrm{H} 200 \times 200 \times 8 \times 12$ & Q345B \\
Brace & $\mathrm{H} 125 \times 125 \times 6.5 \times 9$ & Q235B \\
Link & $\mathrm{H} 250 \times 125 \times 6 \times 9$ & Q235B \\
\hline
\end{tabular}

Four specimens were tested. The length of link segment is an important parameter of EBFs structure, which controls the stiffness, strength, ductility, and behavior of an EBF system [30-32].Three specimens were designed with the length ratio $\rho$ of the link length as variable. The corresponding link length ratios were 1.0, 1.6, and 2.2, respectively. In order to study the influence of connection mode on the EBFs structure, a specimen with $600 \mathrm{~mm}$ link length and welded connection was designed. All the semirigid connection specimens are made of 10.9 grade M20 high-strength bolts. Details of the specimens are shown in Table 2. Details of the frames used in this paper are shown in Figure 2. Details of the connections are shown in Figure 3.

The link length ratio can be defined as follows:

$$
\rho=\frac{e}{M_{P} / V_{P}},
$$

where $e$ is the length of link segment $(\mathrm{mm})$.

According to AISC 341-16 (2016), the plastic moment capacity (Mp) and plastic shear capacity ( $\mathrm{Vp}$ ) of the link section are determined as follows [4]:

$$
\begin{aligned}
M_{P} & =Z_{\text {beam }} F_{y} \\
V_{P} & =0.6 F_{y}\left(d-2 t_{f}\right) \cdot t_{w},
\end{aligned}
$$

where $t_{w}$ is the web thickness of the link, $t_{f}$ is the flange thickness of the link, $d$ is the depth of the link, $Z_{\text {beam }}$ is the plastic section modulus of the link, and $F_{y}$ is the yield strength.

2.2. Mechanical Properties of the Materials. In order to determine the yield state of each component, the steel of each component in this paper is tested under uniaxial tension, and the stress-strain curve of the steel is obtained. According to the curve, the elastic modulus $E$, yield strength $f_{y}$, yield strain $\varepsilon_{y}$, tensile strength $f_{u}$, ultimate strain $\varepsilon_{u}$, and elongation of the steel can be determined.

Cylindrical tensile specimens were made according to the Method of Tensile Testing for Metal Materials at Room Temperature GB/T288.1-2010 [33]. The web and flange of the columns, the beams, the braces, and the link of the EBFs are used as the base materials. There are three specimens for each type, totaling 24 specimens of 8 types. Tensile tests are carried out on the INSTRON/5982 hydraulic universal testing machine for all the specimens. The test values of each group are averaged, and the results are detailed in Table 3. According to the test results, the elastic modulus, yield strength, and ultimate strength of the same batch of steel used in this test basically meet the requirements.
According to the test results, the yielding strain values of each component are shown in Table 4, and the yield state of each component is judged according to these strain values under force control loading.

2.3. Test Configuration. All specimens in the test are installed following the design criteria documented by Chinese National Standard GB 50205-2001 [34]. The 10.9 grade M20 high-strength bolts were first polished and then prestressed with $156 \mathrm{kN}$ (torque is $578 \mathrm{~N} \cdot \mathrm{m}$ ) using a torque wrench. These bolts were installed from the middle part of the region to the surrounding area. The test model and test configuration are detailed in Figures 4 and 5 [35]. In order to prevent large out-of-plane deformation of specimens during loading, an out-of-plane displacement limiting device is designed, as shown in Figure 6. A directional sliding support is used on the column top to ensure that the column top can slide with the actuator in the plane of the specimen, as shown in Figure 7. The column foot is fixed with anchor bolts, as shown in Figure 8.

2.4. Arrangement of Measuring Points. The displacement of the specimen is measured by a linear displacement sensor. In order to obtain the overall lateral displacement, the interlayer displacement of the specimen, and the vertical displacement of the link, linear displacement sensors are installed at the elevation of the frame beam and at both ends of the link. The applied horizontal load and the internal displacement of the actuator are automatically collected by the computer data acquisition system of MTS electrohydraulic servo loading system. Displacement meters are arranged as shown in Figure 9. LD1 and LD2 are laser displacement meters; ND1 and ND2 are needle displacement meters.

The strain results are mainly used to observe the plastic development process of the structure, and the strain of the specimens is measured by resistance strain gauge. In order to obtain the development and distribution of stress and strain during loading process, the strain gauges are arranged at the web and flange of the link, supporting flange, column foot, and the end of the floor beam. As the main energy dissipation component, the strain gauge is mainly arranged on the link. The lateral stiffness of the brace is relatively large, and the horizontal shear force shared by the brace is transferred from the brace to the link to make the link shear. The brace should keep the elastic working state and ensure the transmission of the link. In order to facilitate the analysis of the force change of the brace axial force under the horizontal reciprocating load, the strain gauge is arranged along the axis on the upper and lower flanges of the brace center position. Strain gauges arranged at column foot and brace joint are mainly used to observe the local stress state or plastic development state of the structure. Strain gauges arranged at flange of the floor beam are mainly used to observe the stress state of floor beam. The strain measurement is shown in Figure 9.

According to AISC 341-16, the link rotation angle shall not exceed the following values [4]: 

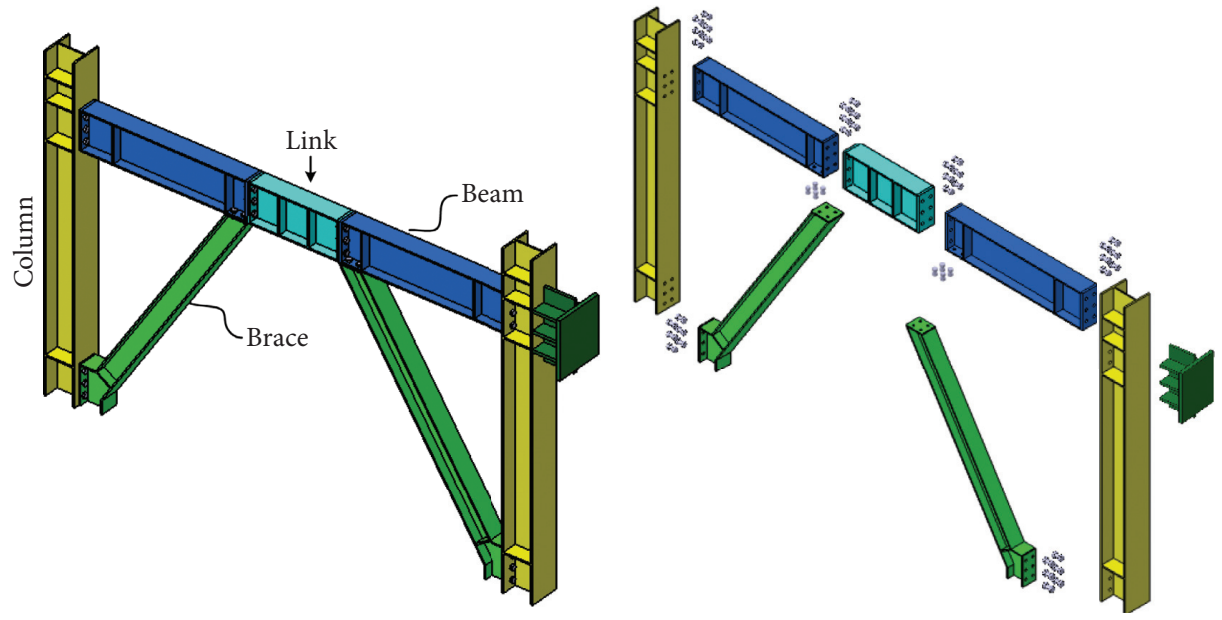

Figure 1: EBFs configuration used in this paper.

TABLE 2: Specimens information.

\begin{tabular}{lcccccc}
\hline Group & Specimen ID & Link length $e(\mathrm{~mm})$ & Length ratio $\rho$ & Intermediate stiffeners & $F(\mathrm{kN})$ & Number of bolts \\
\hline \multirow{3}{*}{ Bolted connection } & PDKB-1 & 400 & 1.0 & 1 at $200 \mathrm{~mm}$ & 200 & 44 \\
& PDKB-2 & 600 & 1.6 & 2 at $200 \mathrm{~mm}$ & 200 & 44 \\
& PDKB-3 & 800 & 2.1 & 3 at $200 \mathrm{~mm}$ & 200 & 44 \\
\hline Welded connection & PDKW-2 & 600 & 1.6 & 2 at $200 \mathrm{~mm}$ & 200 & 0 \\
\hline
\end{tabular}

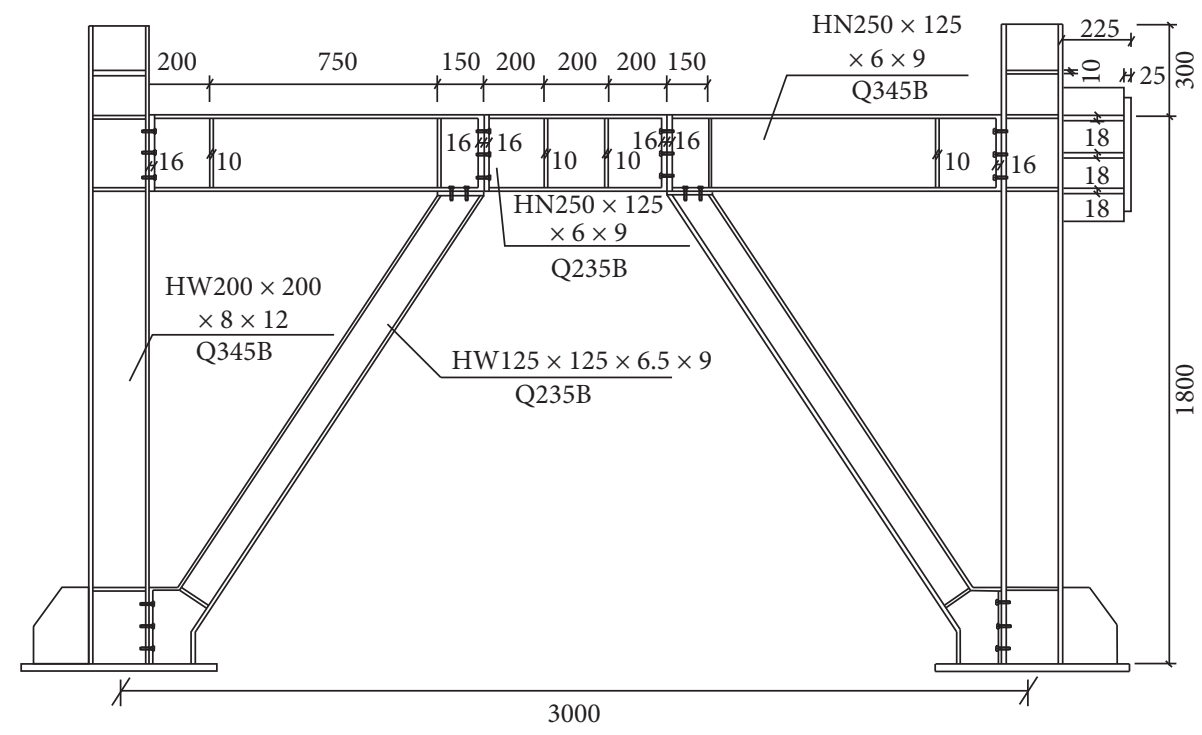

FIgURE 2: Details of the frames used in this paper ( $\mathrm{mm})$.

(1) 0.08 radians for links of length $1.6 M_{p} / V_{p}$ or less

(2) 0.02 radians for links of length $2.6 M_{p} / V_{p}$ or less

(3) The value determined by linear interpolation between the above values for links of length between $1.6 M_{p} / V_{p}$ and $2.6 M_{p} / V_{p}$.

The link rotation angle can be estimated using the procedure explained in the Commentary to AISC341-05. As shown in Figure 10, an EBF deforms in a rigid-plastic mechanism and the link rotation angle can be expressed as a function of the column rotation angle $(\theta)$ as follows $[36,37]$ :

$$
\gamma=\frac{L}{e} \theta
$$

where $\theta=\delta / h$, and $L=$ bay width, $h=$ story height, and $\delta=$ plastic story drift which can be conservatively taken as the design story drift $(\delta)$.

The lateral load was applied by $1000 \mathrm{kN}$ MTS actuators reacting onto the strong wall. The frame columns were truly pin-connected at their base such that the loading system subjected the link to constant shear along its length, $V_{\text {link}}$, and reverse curvature bending, where [38] 


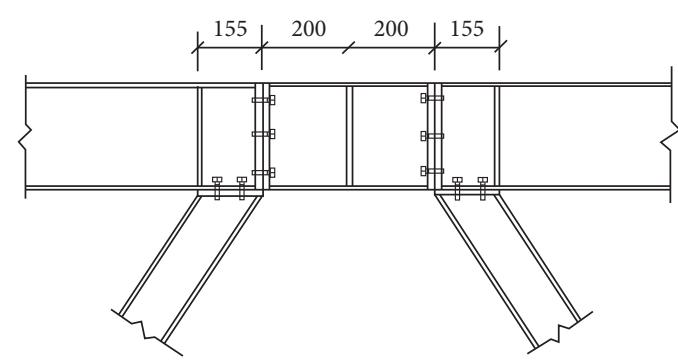

(a)

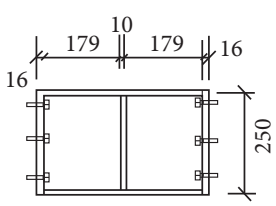

(b)

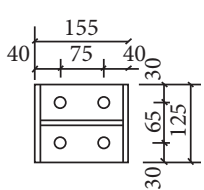

(c)

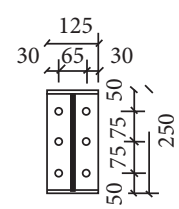

(d)

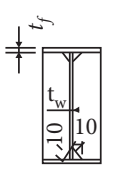

(e)

Figure 3: Details of the connections (mm). (a) Detailing of bolted connections. (b) Link connection. (c) Brace connection. (d) End plate of link. (e) Ribbed plate of link.

TABLe 3: Test results of the steel material properties.

\begin{tabular}{lccccc}
\hline Test & $E(\mathrm{GPa})$ & $f_{y}(\mathrm{MPa})$ & $\varepsilon_{y}(\%)$ & $f_{u}(\mathrm{MPa})$ & 536 \\
\hline BW & 201 & 369 & 0.18 & 530 & Elongation $(\%)$ \\
BF & 227 & 356 & 0.18 & 543 & 29 \\
CW & 224 & 379 & 0.21 & 526 & 30 \\
CF & 224 & 337 & 0.179 & 461 & 34 \\
BRW & 220 & 334 & 0.165 & 460 & 28 \\
BRF & 225 & 289 & 0.167 & 447 & 35 \\
LW & 236 & 271 & 0.163 & 427 & 30 \\
LF & 241 & 261 & 0.157 & 27 \\
\hline
\end{tabular}

Note. $E$ is the elastic modulus of the material, $f_{y}$ is the yield strength, $\varepsilon_{y}$ is the yield strain, $f_{u}$ is the tensile strength, and Elongation is the elongation at break.

TABLE 4: Yield strain of each member.

\begin{tabular}{lcccccrrr}
\hline \multirow{2}{*}{ Position } & \multicolumn{2}{c}{ Beam } & \multicolumn{2}{c}{ Column } & \multicolumn{2}{c}{ Brace } & \multicolumn{2}{c}{ Link } \\
& Flange & Web & Flange & Web & Flange & Web & Flange & Web \\
\hline Yield strain $(\mu \varepsilon)$ & 1800 & 1800 & 1790 & 2100 & 1670 & 1650 & 1630 \\
\hline
\end{tabular}

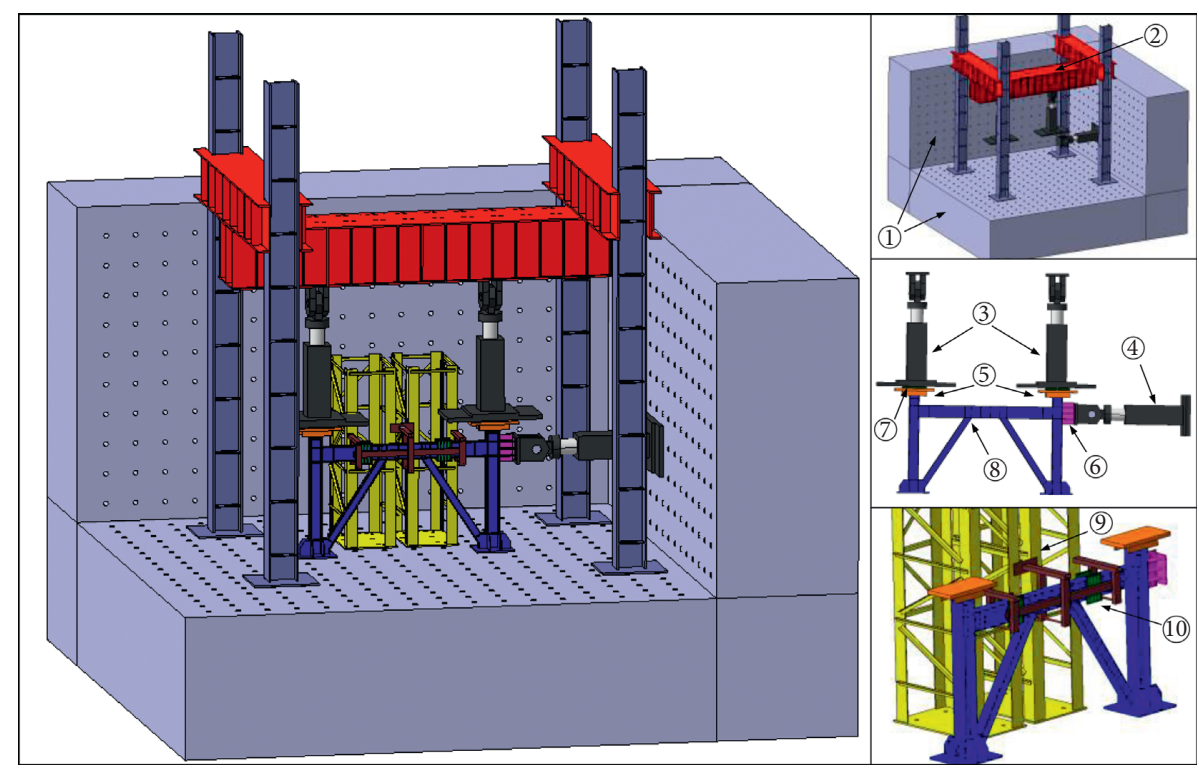

Figure 4: Test model. (1) Floor and reaction wall; (2) reaction frame; (3) $2 \times 2000 \mathrm{kN}$ actuator; (4) $1000 \mathrm{kN}$ actuator; (5) columns support; (6) loading plate; (7) column base bearing; (8) test specimen; (9) support truss; (10) lateral supports. 


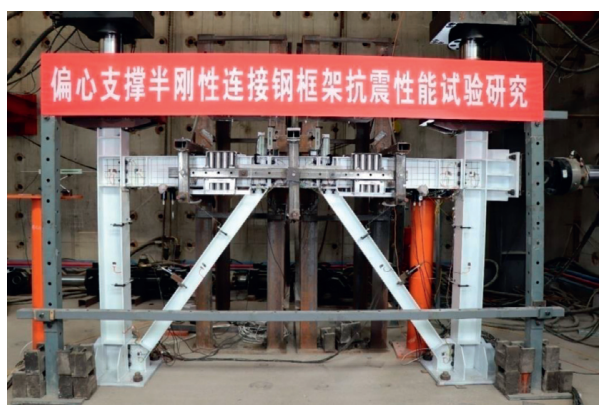

FIgURE 5: Test configuration.
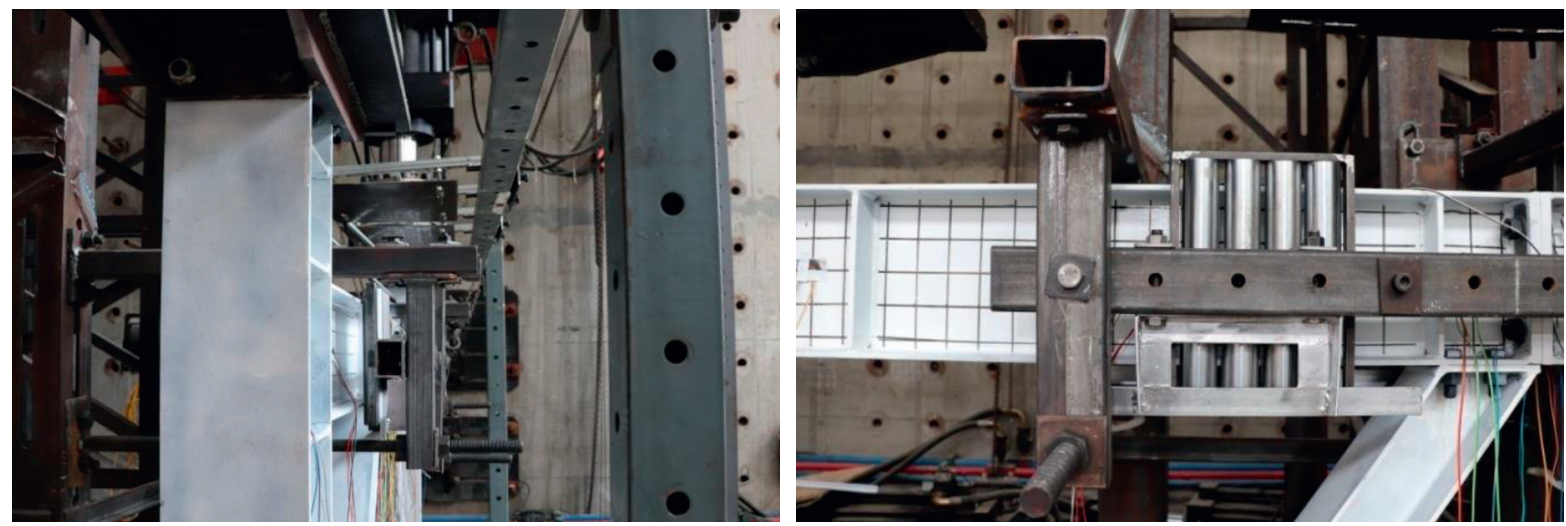

Figure 6: Out-of-plane deformation limiting device.

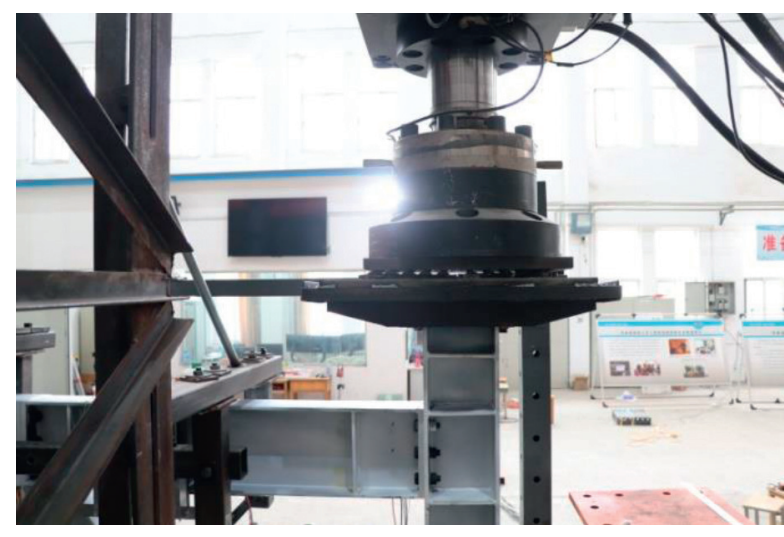

Figure 7: Column top actuator.

$$
V_{\text {link }}=F_{\text {actuator }} \frac{h}{L}
$$

2.5. Load Procedures. The mixed force-displacement control loading system is adopted in the test loading. First, the load is controlled by force. When the specimen reaches the yield state, the displacement control is used until the specimen is destroyed. According to the Code for Seismic Testing of Buildings (JCJ/T101-2005) [39], before yielding, load control and graded loading should be adopted to reduce the differential loading before approaching cracking and yielding loads; after yielding, deformation control should be adopted to obtain the maximum displacement of the specimen when

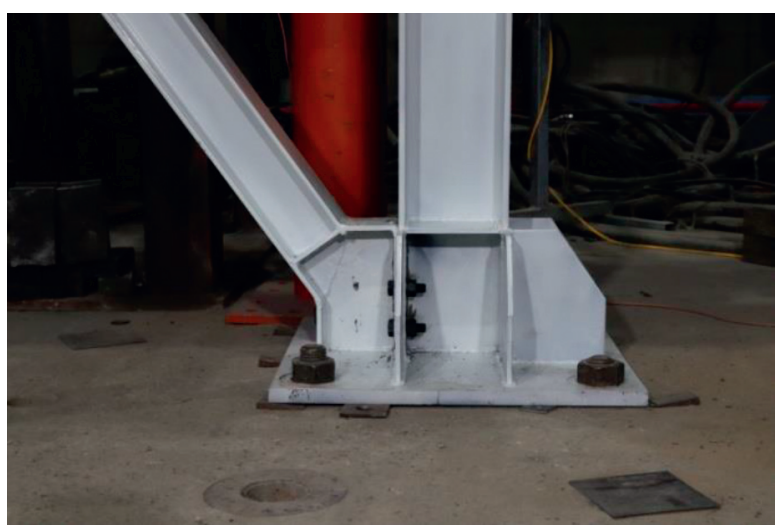

Figure 8: Column foot fixation.

yielding, and the maximum displacement of the specimen when yielding should be controlled by gradation, and repeated loads should be applied three times at each level.

2.5.1. Preloading Stage. Firstly, the vertical actuator is used to exert $200 \mathrm{kN}$ axial pressure on the top of the column to simulate the axial compression of the frame column(s) and ensure that it remains unchanged throughout the test process. Horizontal displacement load will be applied after the response of frame specimens is stable under axial compression, and the horizontal load will be maintained in the range of $+100 \mathrm{kN}$ to ensure good contact between the frame specimens and the test device. Repeated tests were 


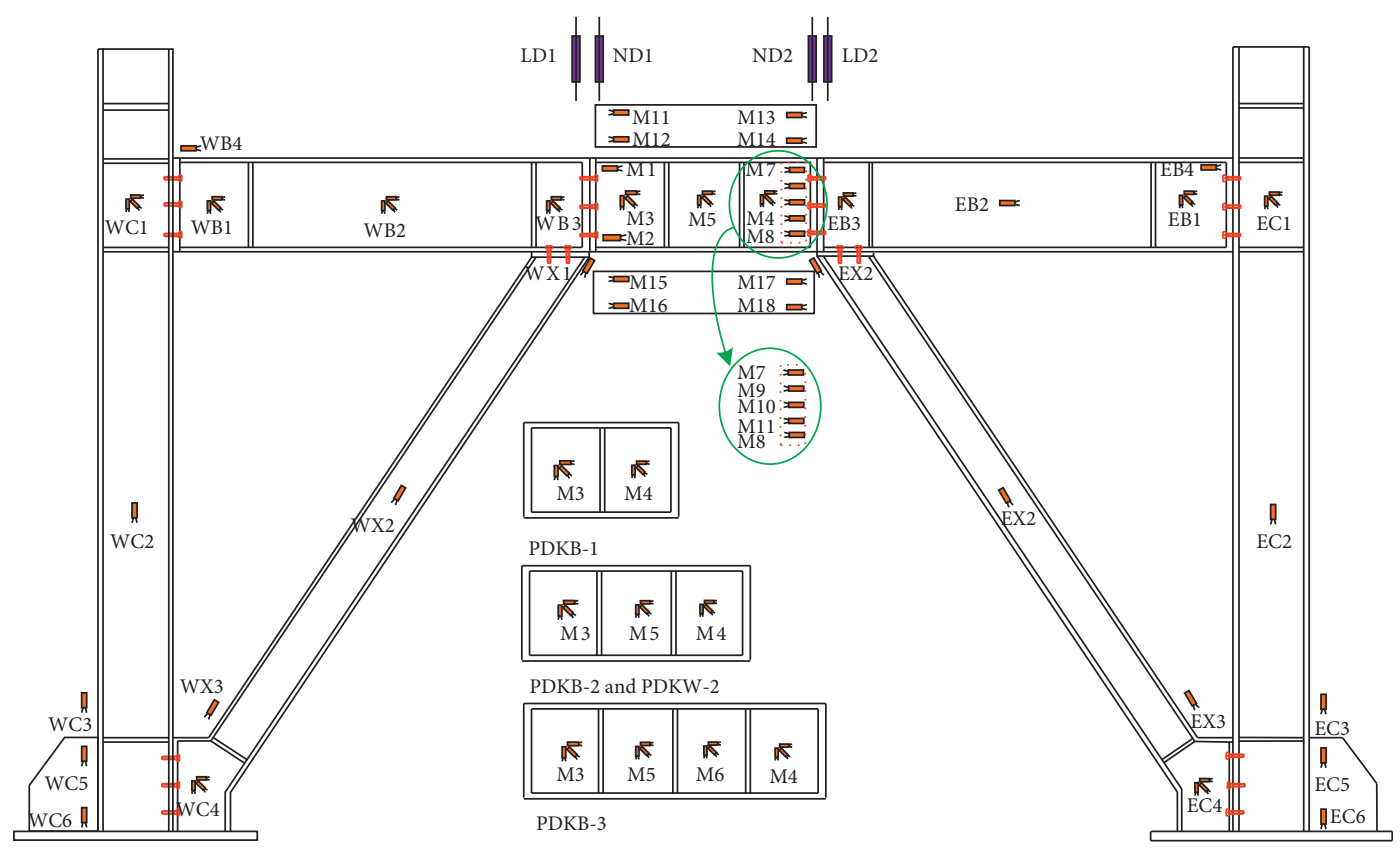

FIgURE 9: Arrangement of strain gauges and displacement meters.

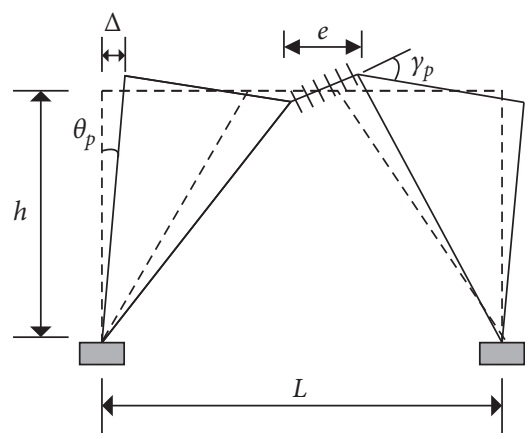

Figure 10: Free body diagram and deformation mechanism of EBF.

conducted three times to check whether the sensors and strain gauges were working properly and check the monitoring strain gauges to determine the location of the first plastic strain of the frame and to calculate the yield loaddisplacement $\delta_{y}$. When the recorded maximum strain reached the values in Table 5, $\delta_{y}$ and $F_{y}$ of both specimens are measured as shown in Table 6.

2.5.2. Loading Method. After determining $\delta_{y}$ of the frame specimens in the preloading stage, all the horizontal actuators return to zero and are loaded formally in accordance with the loading mode of Figure 11. Actuator is pushed forward as positive load and vice versa as negative load. Three cycles of positive and negative loads are applied to each grade, and the planar actuator of the strong axis is put to zero after the application. During the test, if it is found that the frames are broken, the local buckling failure is obvious, or the force in the hysteretic curve monitored by the test is less than $85 \%$ of the ultimate bearing capacity, the test will be terminated. The loading protocol is shown in Figure 11.

\subsection{Experimental Phenomena, Failure Modes, and Results}

2.6.1. Experimental Phenomena. The experimental phenomena of eccentrically braced semirigid steel frames are similar. This paper takes specimen PDKB- 1 as an example, as shown in Table 7. The experimental phenomena of specimen PDKB-1 are shown in Figure 12. In the initial stage of loading, there is no obvious deformation of the end plate. When the load increases to $2 \delta_{y}$, the bolts and bolt holes have slight relative dislocation sound. When the load increases to $4 \delta_{y}$, as shown in Figure 12(a), the end plates of the link and the beam produce obvious dislocation and produce $2 \mathrm{~mm}$ cracks, with obvious relative dislocation sound at the joint; the end plate of the link begins to buckle. Figure 12(b) shows that when the load is $5 \delta_{y}$, the spray paint at the column base falls off partially; Figure 12(c) shows that when the load is $7 \delta_{y}$, the flange of the link will buckle, and the gap between the end plates of the link and the beam will expand, resulting in a $10 \mathrm{~mm}$ gap; Figure 12(d) shows that when the load is $9 \delta_{y}$, the web of the link will fracture. 
TABle 5: $M_{P}$ and $V_{P}$ of links.

\begin{tabular}{lcccccc}
\hline$d(\mathrm{~mm})$ & $t_{w}(\mathrm{~mm})$ & $t_{f}(\mathrm{~mm})$ & $Z_{\text {beam }}\left(\mathrm{cm}^{3}\right)$ & $F_{y}(\mathrm{MPa})$ & $M_{p}(\mathrm{kN} \cdot \mathrm{m})$ & $V_{p}(\mathrm{kN})$ \\
\hline $\mathbf{2 5 0}$ & 6 & 9 & 309.4 & 271 & 83.5 & 225.5 \\
\hline
\end{tabular}

TABLE 6: Yield displacement and corresponding force.

\begin{tabular}{lcc}
\hline Specimen & Yield $\delta_{y}(\mathrm{~mm})$ & Force $F_{y}(\mathrm{kN})$ \\
\hline PDKB-1 & 3.81 & 247 \\
PDKB-2 & 2.89 & 207 \\
PDKB-3 & 3.67 & 162 \\
PDKW-2 & 2.67 & 242 \\
\hline
\end{tabular}

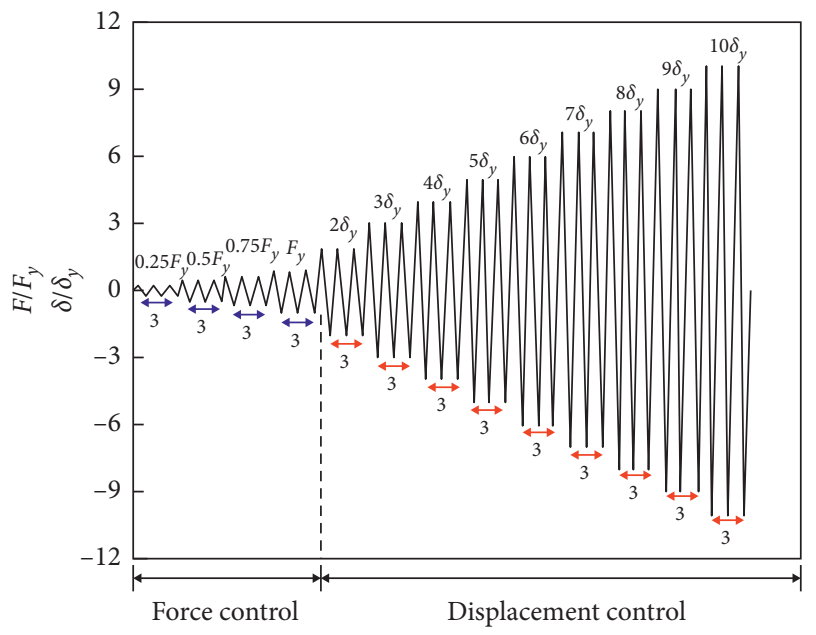

FIGURE 11: Loading protocol.

The experimental phenomena of specimen PDKB-2 are shown in Figure 13. Figure 13(a) shows that when the load is $3 \delta_{y}$, the end plate of the link begins to buckle; Figure 13(b) shows that when the load is $6 \delta_{y}$, the flange of the link will buckle; Figure 13(c) shows the overall deformation of the structure when the load is $7 \delta_{y}$; Figure $13(\mathrm{~d})$ shows that when the load is $8 \delta_{y}$, the weld of the end plate of the link will fracture.

The experimental phenomena of specimen PDKB-3 and PDKB-4 are shown in Figures 14 and 15.

2.6.2. Failure Modes. The failure phenomena of PDKB-1, PDKB-2, and PDKB-3 are shown in Figure 16 and those of PDKW-2 are shown in Figure 17. The failure mechanism of the specimens is shown in Table 8 .

2.6.3. Experimental Results. Table 9 shows the results of test displacement and actuator load. It can be seen that the drift of eccentrically braced semirigid frame decreases with the increase of the length ratio of link. The drift of the specimen with the length ratio of 2.1 is the largest, followed by the specimen with the length ratio of 1.0 , and the specimen with the length ratio of 1.6 is the smallest. Compared with welded specimens, the drift of semirigid joints is larger. The ultimate drift of semirigid joints
(PDKB-2) is $32.2 \%$ higher than that of welded joints (PDKW-2). However, the ultimate bearing capacity of welded joints (PDKW-2) is 24.9\% higher than that of semirigid joints (PDKB-2).

Table 10 shows the test results of the rotation and shear capacity of the link. For the semirigid joint specimens, the shear force decreases with the increase of the length ratio of the link. Short link has the highest shear force. Under the same condition, the shear capacity of semirigid joint is $24.8 \%$ lower than that of welded joint. However, the inelastic rotation of semirigid joint is $24.4 \%$ higher than that of welded joint. The links with length ratios of 1 and 1.6 have achieved and exceeded the ductility acceptance criteria of $0.08 \mathrm{rad}$ inelastic link rotation prescribed by 2005 AISC seismic provisions (AISC2005). Among them, the inelastic rotation of the link of PDKB-1 is 0.14 , and that of PDKB-2 is 0.088 . The specimen with a length ratio of 2.1 has achieved and exceeded the ductility acceptance criteria of 0.02 rad inelastic link rotation prescribed by 2005 AISC seismic provisions (AISC2005). The inelastic rotation of the link of PDKB-3 is 0.076 .

\section{Analysis and Discussion of Test Results}

In order to evaluate the seismic performance and capability of semirigid-jointed steel frame with eccentrically braced assemblies, in this paper, the strength, stiffness, ductility, cumulative energy consumption, and stiffness degradation of frame structures are analyzed.

3.1. Hysteretic Behavior. Hysteretic curve is the force-displacement curve of specimens under repeated loads, which reflects the deformation characteristics, stiffness degradation, and energy dissipation capacity of specimens [33]. In this paper, the hysteretic curves of load-displacement relationship are established based on the constrained reactions at the loading end and the displacements collected by the displacement meter. Figures 18(a) and 18(c) are hysteretic curves of EBFs with end-plate-bolt connections. It is found that these hysteretic curves are "bowed" and have obvious "pinch" phenomenon. It is mainly affected by the slip between the end plate of the beam and the end plate of the link. After the load reaches $2 \delta_{y}$, the big "noise" produced by the end plate slip is accompanied by each load. Figure 18(d) shows the hysteretic curve of welded EBFs, which is "shuttle" and has full hysteretic curve. By comparison and analysis, it can be seen that, with the increase of the length of link, the phenomenon of pinching of hysteretic curve of eccentrically braced semirigid-jointed steel frames becomes more and more obvious. The hysteretic curve of frame with short link is fuller than that of frame with medium-length link, and its energy dissipation performance is better. 
TABLE 7: Experimental phenomena of specimen PDKB-1

\begin{tabular}{lcc}
\hline$* \delta_{y}$ & Strain gauge showing yield & Experimental phenomena \\
\hline $\mathbf{1}$ & M7 & Measure point M7 yield first \\
$\mathbf{2}$ & M1 M10, M14, EB4, EC3, WC3 & All points on the web of link yield \\
$\mathbf{3}$ & M11, M12 & Measure points EC3, WC3 on the column, and EB4 on the beam yield \\
Measure points M11 and M12 on the flange of link yield \\
$\mathbf{4}$ & WX3 & End plate of link buckling \\
$\mathbf{5}$ & $\mathrm{EB} 3$ & Measure point WX3 on the brace yield \\
$\mathbf{6}$ & $\mathrm{EX3}$ & Paint on the leg of the column flaked off \\
$\mathbf{7}$ & $\mathrm{M} 13, \mathrm{~EB} 2, \mathrm{EC} 4$ & End plate of link buckling increased \\
$\mathbf{8}$ & $\mathrm{M} 15$ & Flange of link buckling \\
$\mathbf{9}$ & $\mathrm{EB} 1$ & Web of link buckling
\end{tabular}

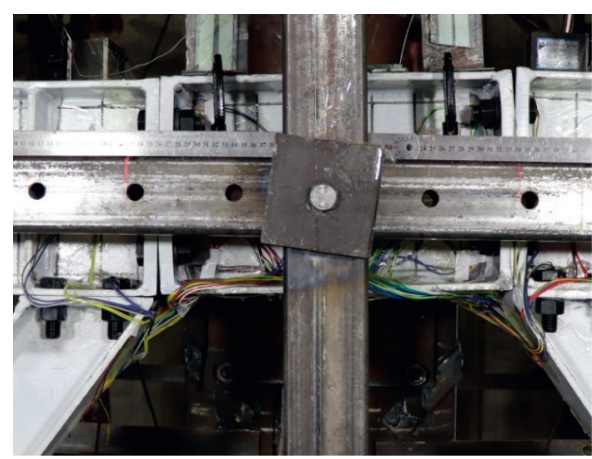

(a)

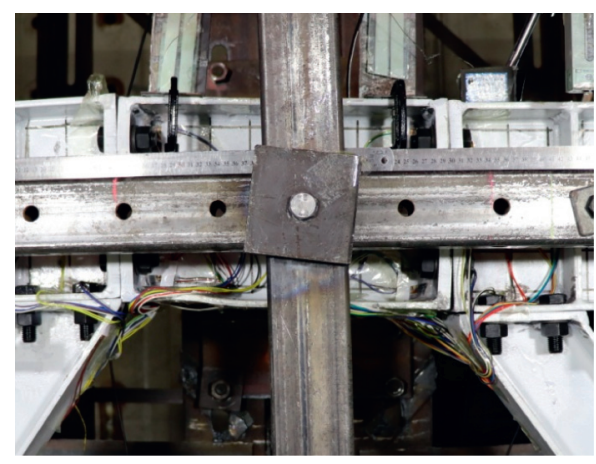

(c)

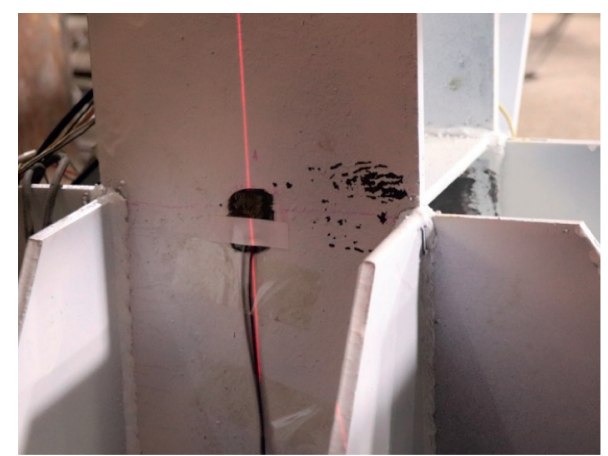

(b)

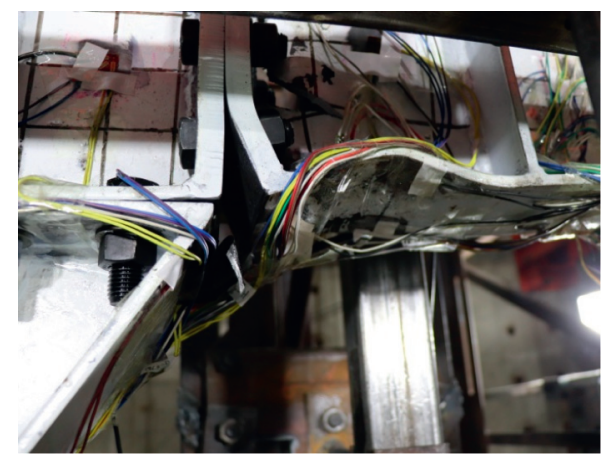

(d)

FIGURE 12: Experimental phenomena of specimen PDKB-1. (a) Deformation at $4 \delta_{y}$. (b) Deformation at $5 \delta_{y}$. (c) Deformation at $7 \delta_{y}$. (d) Deformation at $9 \delta_{y}$.

3.2. Force-Drift Envelope Curves. The force-drift envelope curve is the outer envelope of the hysteretic curve, which reflects the strength, stiffness, ductility, and collapse resistance of structural members [40]. Figure 19 are the forcedrift envelope curves of specimens. Figure 19(a) shows the force-drift envelope curves of PDKB-2 and PDKW-2. The two specimens only have different connection modes and the other parameters are the same. The analysis shows that the ultimate bearing capacity of welded EBFs is higher than that of end-plate bolted EBFs, but the ductility is slightly worse. The maximum bearing capacity of welded frame is $24.2 \%$ higher than that of semirigid joint EBFs. Figure 19(b) shows the force-drift envelope curves of PDKB-1, PDKB-2, and PDKB-3. The three specimens have different lengths of links and the other parameters are the same. It shows that the differences in the ultimate bearing capacity of the structure with the link length ratios of 1.0 and 1.6 are small, while they will decrease obviously with the link length ratio of 2.2.

3.3. Rigidity Degradation. The rotational stiffness of frames is defined as the tangent stiffness of force-drift hysteretic curve before the yielding stage. When the frames enter the plastic bearing state, the force and drift show obvious nonlinear characteristics. For convenience, secant stiffness is often used to express the rotational stiffness of joints after entering the plastic state. Considering the cyclic loadings in the quasi-static test, the force bearing capacities and 


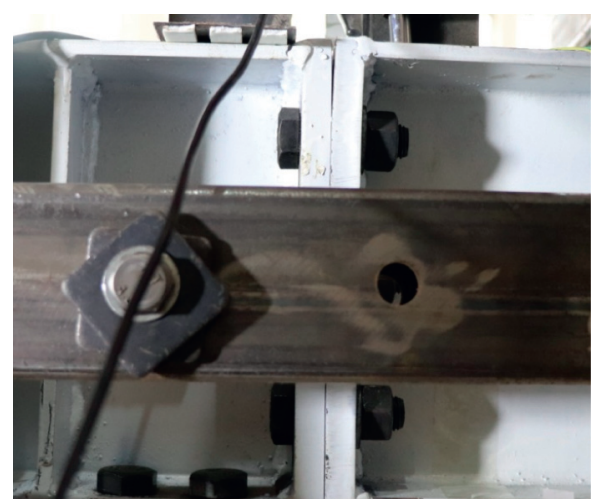

(a)

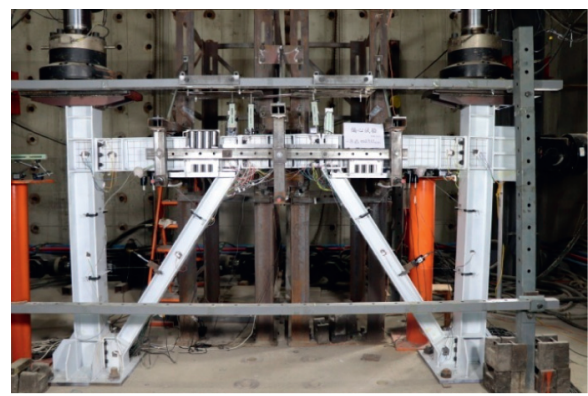

(c)

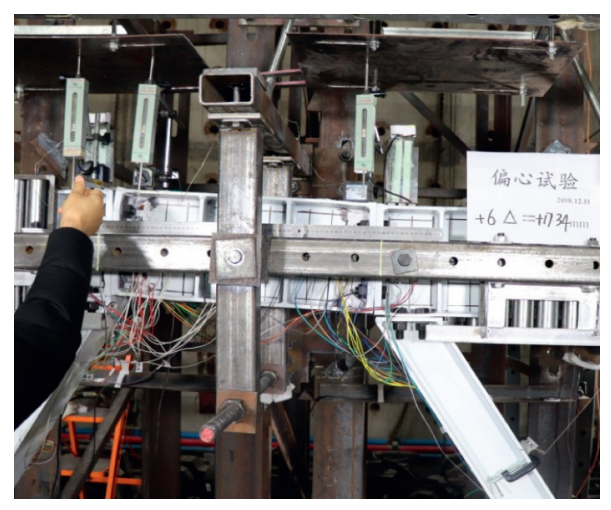

(b)

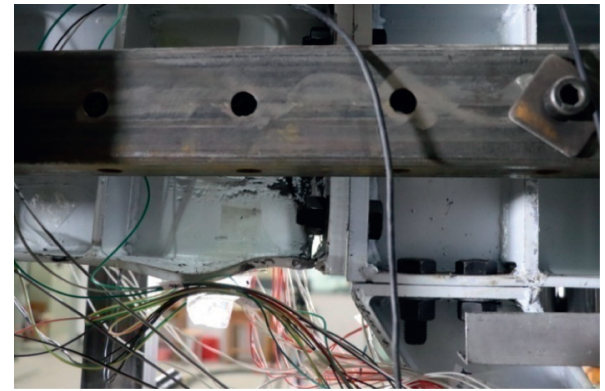

(d)

FIgURE 13: Experimental phenomena of specimen PDKB-2. (a) Deformation at $3 \delta_{y}$. (b) Deformation at $6 \delta_{y}$. (c) Deformation at $7 \delta_{y}$. (d) Deformation at $8 \delta_{y}$.

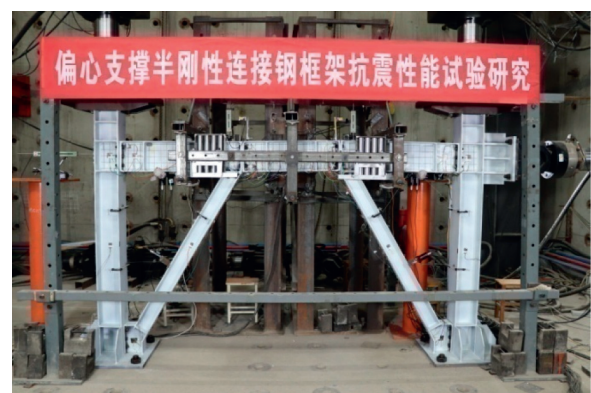

(a)

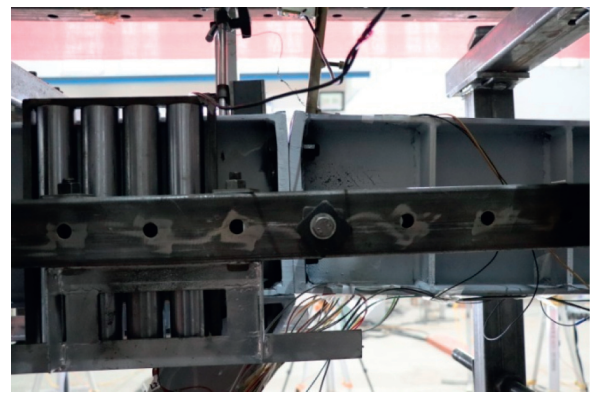

(c)

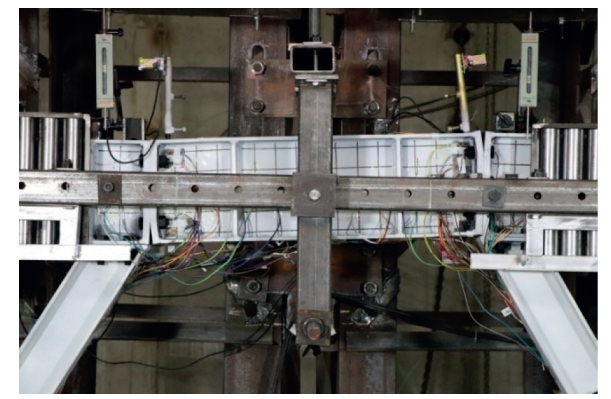

(b)

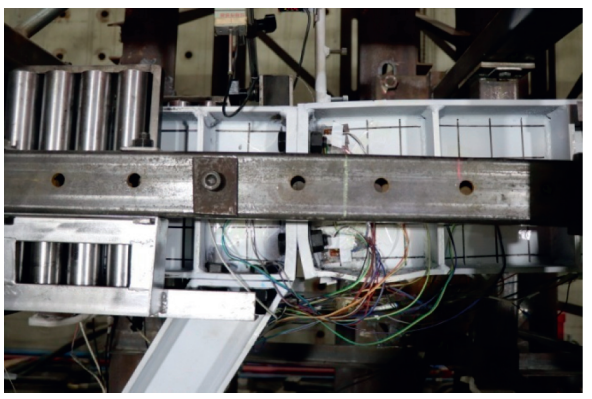

(d)

FIGURE 14: Experimental phenomena of specimen PDKB-3. (a) Deformation at $4 \delta_{y}$. (b) Deformation at $6 \delta_{y}$. (c) Deformation at $7 \delta_{y}$. (d) Deformation at $8 \delta_{y}$. 


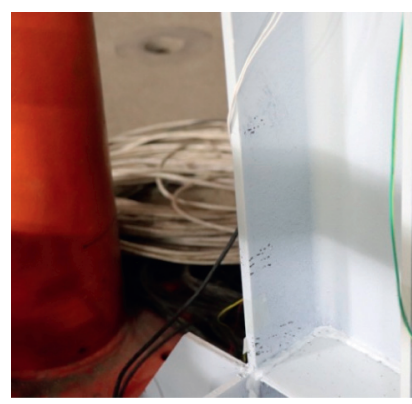

(a)

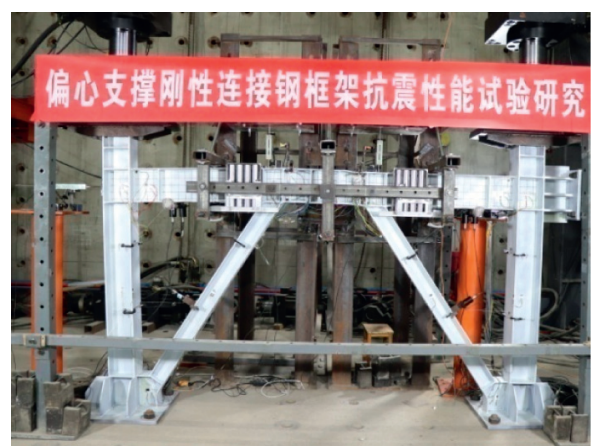

(c)

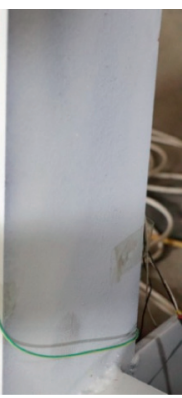

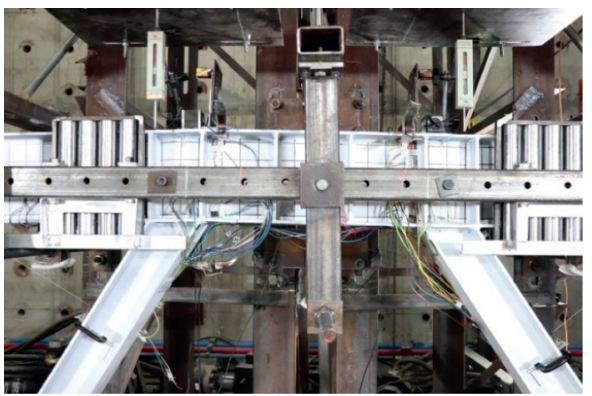

(b)

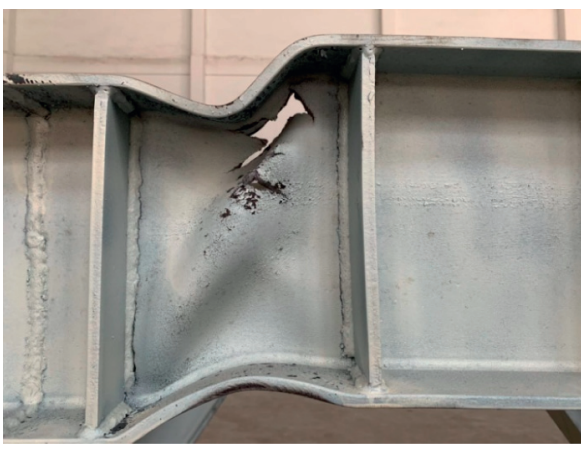

(d)

Figure 15: Experimental phenomena of specimen PDKW-1. (a) Deformation at $3 \delta_{y}$. (b) Deformation at $6 \delta_{y}$. (c) Deformation at $7 \delta_{y}$. (d) Deformation at $8 \delta_{y}$.

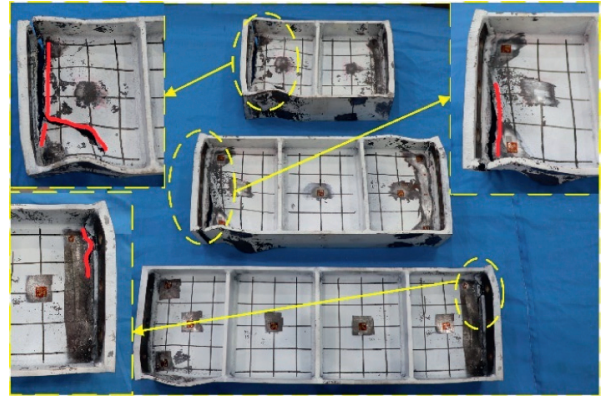

FIGURE 16: Failure modes of semirigid joints.

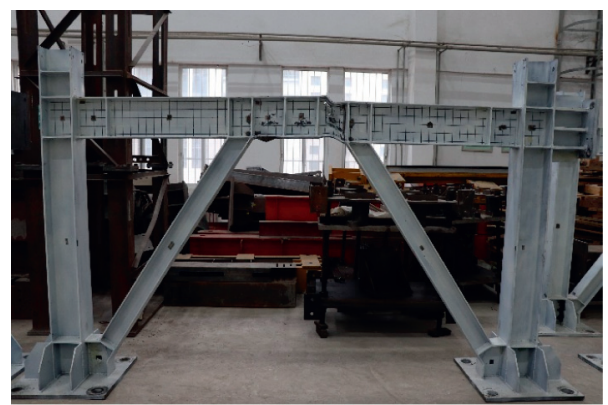

Figure 17: Failure modes of rigid-jointed specimens.

corresponding drifts have both positive and negative values, so the secant stiffness of the joints is determined by the ratio of the absolute sum of the positive and negative force bearing capacity and the absolute sum of the corresponding maximum drift under the same load level. Therefore, the drift stiffness of the frame is defined as 
TABLE 8: Mechanism of failure of different specimens.

\begin{tabular}{lc}
\hline Specimens & Observed mechanism of failure \\
\hline PDKB-1 & Fracture at the web of link, severe flange local buckling \\
PDKB-2 & End plate fracture at the toe of weld between end plate and link flange \\
PDKB-3 & Fracture at the web of link, severe flange local buckling \\
PDKW-2 & Link shear failure \\
\hline
\end{tabular}

TABle 9: Results of test displacement and actuator load.

\begin{tabular}{lcccc}
\hline Specimen ID & Yield displacement $\delta_{y}(\mathrm{~mm})$ & Yield force $F_{y}(\mathrm{kN})$ & Maximum displacement $\delta_{u}(\mathrm{~mm})$ & Maximum force $F_{u}(\mathrm{kN})$ \\
\hline PDKB-1 & 3.81 & 247 & 35.30 & 710 \\
PDKB-2 & 2.89 & 207 & 28.88 & 631 \\
PDKB-3 & 3.67 & 162 & 36.77 & 538 \\
PDKW-2 & 2.67 & 242 & 24.63 & 788 \\
\hline
\end{tabular}

TABle 10: Test results.

\begin{tabular}{lcccccc}
\hline \multirow{2}{*}{ Specimen ID } & \multicolumn{2}{c}{ Link rotation } & \multicolumn{2}{c}{ Link shear force } & \multicolumn{2}{c}{ Frame drift } \\
& $\gamma_{y}(\mathrm{mrad})$ & $\gamma_{\text {ult }}(\mathrm{mrad})$ & $V_{y}(\mathrm{kN})$ & $V_{\text {ult }}(\mathrm{kN})$ & $\theta_{y}(\%)$ & 0.21 \\
\hline PDKB-1 & 15.9 & 147 & 148 & 426 & 1.96 \\
PDKB-2 & 8.2 & 80 & 124 & 378.6 & 0.16 \\
PDKB-3 & 7.6 & 77 & 97 & 322.8 & 0.20 \\
PDKW-2 & 7.4 & 68 & 145 & 472.8 & 0.14 \\
\hline
\end{tabular}

$$
K_{j}=\frac{\left|+F_{j}\right|+\left|+F_{j}\right|}{\left|+\Delta_{j}\right|+\left|-\Delta_{j}\right|}
$$

where $F_{j}$ and $\Delta_{j}$ are the maximum load and the corresponding lateral displacement under the $j$ th loading level, respectively. According to formula (6), the initial drift stiffness of all frame specimens in all directions is calculated. The calculation results are detailed in Table 11 .

In order to analyze the degradation degree of frame stiffness, the rotational stiffness of all frames under the yield state is defined as the initial rotational stiffness of the frames, and the stiffness of each joint in all directions is normalized. With the increase of load level, the drift stiffness will degenerate on the basis of the initial rotational stiffness. The rigidity degradation curve of the specimen is shown in Figure 20:

$$
\lambda_{j}=\frac{K_{j}}{K_{0}} .
$$

The influence of semirigid joints on the initial stiffness of EBFs is analyzed in Table 11, and the influence of the link lengths on the initial rotation stiffness is also analyzed. The following conclusions can be drawn: (1) The initial rotation stiffness of PDKB-2 is $7.3 \%$ lower than that of PDKW-2. It shows that semirigid joint has little effect on the initial rotational stiffness of EBFs. (2) The initial rotational stiffness of EBFs with long link is lower than that of short link.

3.4. Ductility. The ductility is an important index to design the seismic performance of composite structures [41]. The angular displacement ductility coefficient $\left(\mu_{\Delta}\right)$ can be calculated as

$$
\mu_{\Delta}=\frac{\Delta_{u}}{\Delta_{y}}
$$

where $\Delta_{u}$ is the maximum displacement and $\Delta_{y}$ is the yield displacement.

The yield displacement $\Delta_{y}$ is obtained by the general yield loads method [41], as shown in Figure 21.

The ductility coefficients of the specimens are calculated by formula (3), as shown in Table 12. The analysis shows that the ductility coefficients of all specimens are between 2 and 4 , which indicates that the ductility performance is good. As the thickness of the end plate increases, the ductility coefficient of the specimens decreases. The ductility coefficient of specimens with semirigid connection is higher than that of specimens with rigid connection.

3.5. Energy Dissipation Capacity. The energy dissipation capacity of structures is usually assessed by the trend of cumulative energy dissipation and the equivalent viscous damping coefficient $h_{e}$. Figure 22 shows the cumulative energy dissipation charts of four eccentrically braced semirigid-jointed steel frames.

Figure 22 shows the cumulative energy consumption of each specimen. With the increase of link length, the cumulative energy consumption of eccentrically braced semirigid steel frames decreases. Among them, the cumulative energy consumption of PDKB-1 is the largest. When damaged, the maximum cumulative energy consumption of PDKB-1 is $31.38 \mathrm{~kJ}$, that of PDKB-2 is $16.46 \mathrm{~kJ}$, and that of PDKB-3 is $14.59 \mathrm{~kJ}$. When the link length ratio increases 


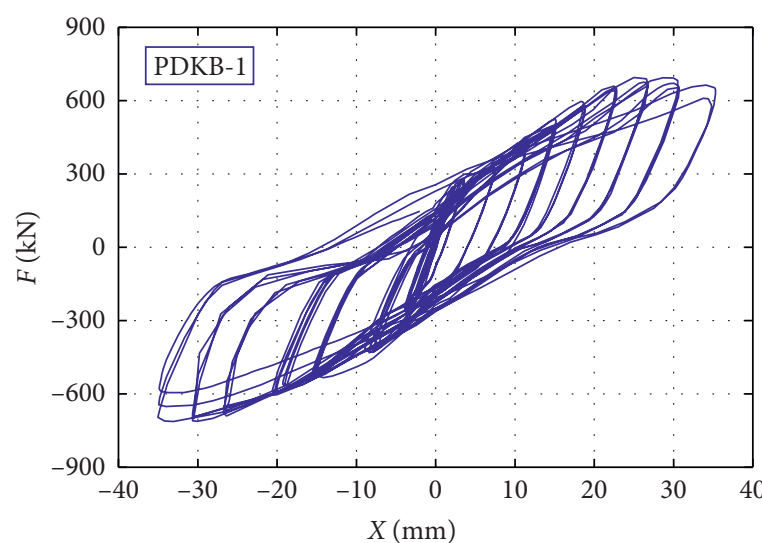

(a)

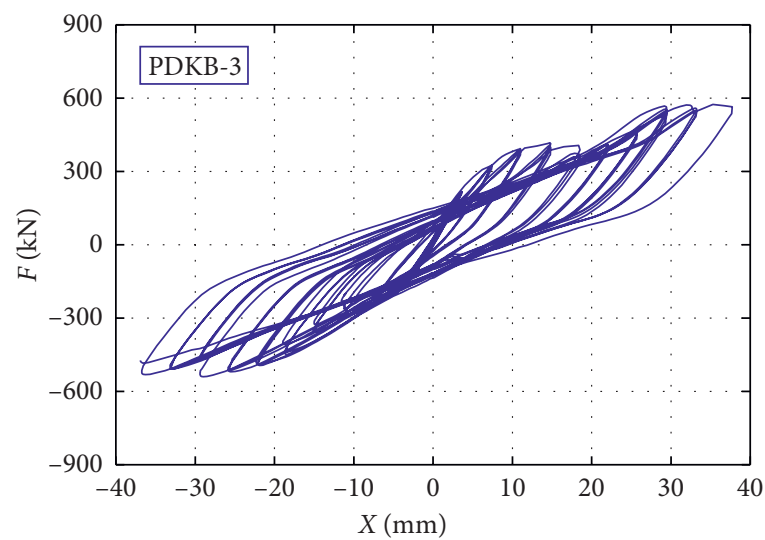

(c)

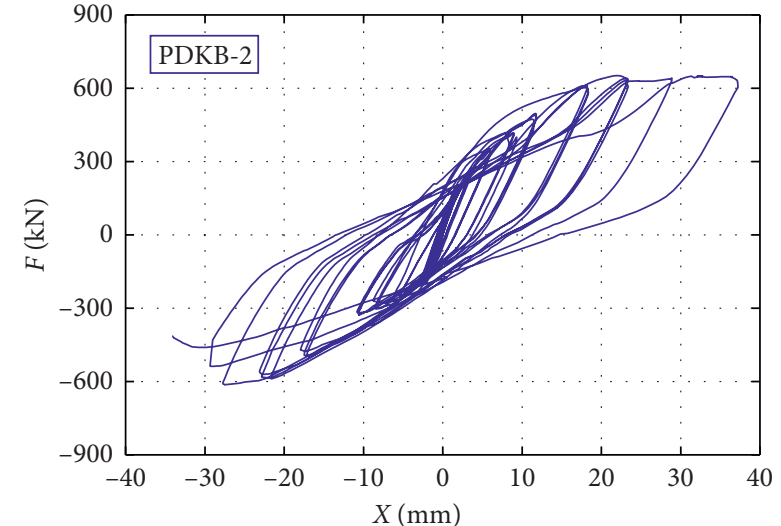

(b)

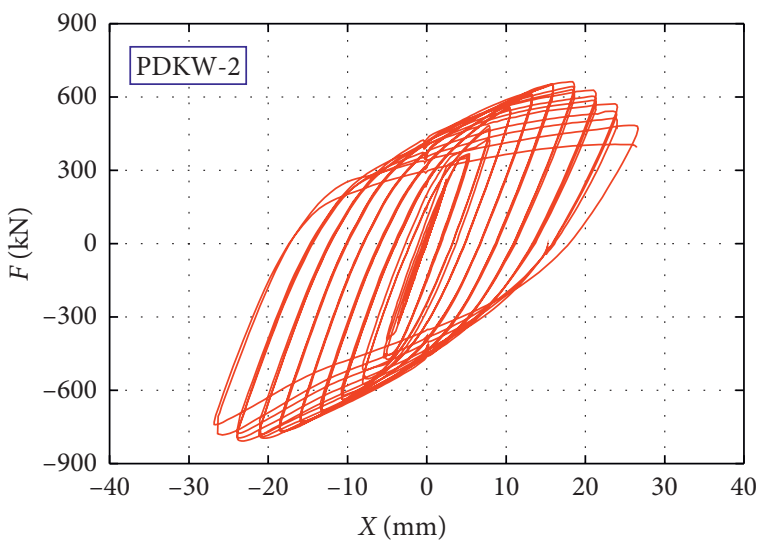

(d)

FIGURE 18: Force-drift hysteresis curves.

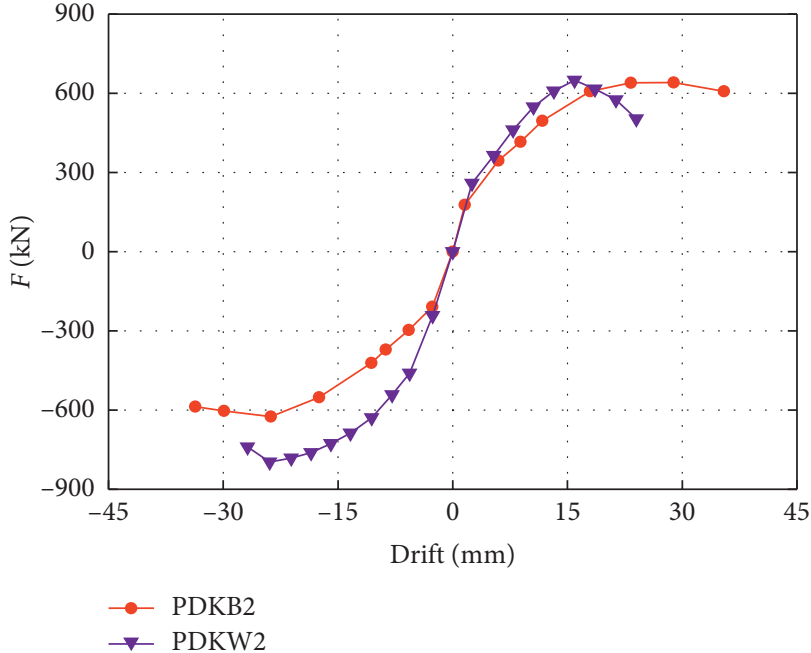

(a)

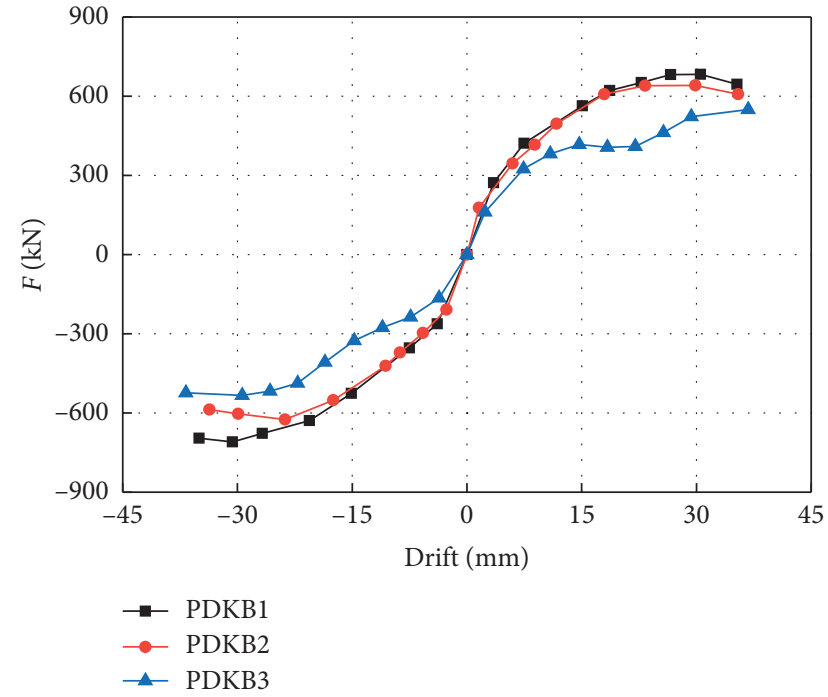

(b)

Figure 19: Force-drift envelope curves of specimens.

from 1.0 to 1.6, the maximum cumulative energy dissipation of structure decreases by $47.04 \%$, and the energy dissipation capacity decreases obviously. When the link length ratio increases from 1.6 to 2.1, the maximum cumulative energy consumption of the structure decreases by $11.36 \%$. It shows that the eccentrically braced semirigid steel frame with the 
TABLE 11: Rigidity degradation coefficients of specimens.

\begin{tabular}{lcccc}
\hline Specimens & PDKB-1 & PDKB-2 & PDKB-3 & PDKW-2 \\
\hline$K_{0}(\mathrm{kN} / \mathrm{mm})$ & 72.6 & 90.7 & 53.9 & 97.8 \\
\hline
\end{tabular}
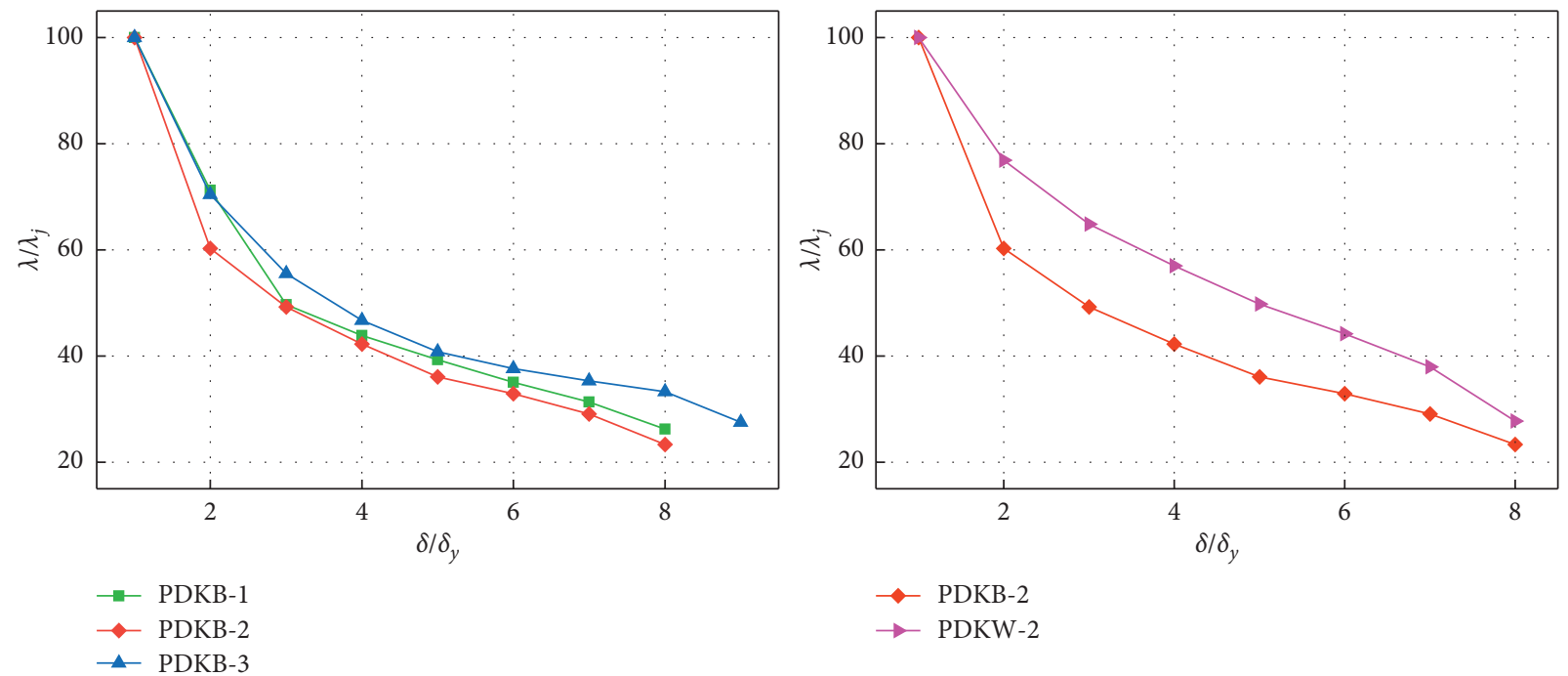

FIgURE 20: Rigidity degradation curve.

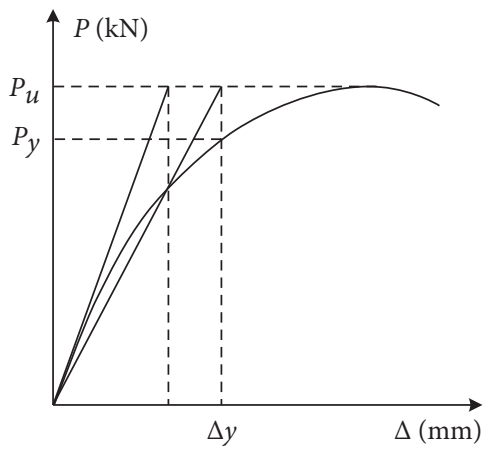

Figure 21: General yield loads method.

TABLE 12: Ductility coefficients.

\begin{tabular}{|c|c|c|c|c|}
\hline Specimens & PDKB-1 & PDKB-2 & PDKB-3 & PDKW-2 \\
\hline Yield displacement & 13.5 & 10.2 & 9.5 & 10.1 \\
\hline Maximum displacement & 35.3 & 28.88 & 36.77 & 24.63 \\
\hline Ductility coefficients & 2.61 & 2.83 & 3.87 & 2.44 \\
\hline
\end{tabular}

short link has the best energy dissipation capacity. At the initial stage of loading, all the specimens show good energy dissipation capacities. When it is continuously loaded to $4 \delta$, relative dislocation occurs between the link and the beam, and obvious buckling occurs at the end plate of the link, The cumulative energy dissipation capacity of the structure is insufficient. The maximum cumulative energy consumption of eccentrically braced rigid-jointed steel frames is $27.98 \mathrm{~kJ}$, which is $170 \%$ higher than that of semirigid-jointed steel frames. The main reason is that the end plate of the link is thin. When it is loaded to $4 \delta$, the end plate buckles obviously, and the bearing capacity of the structure is lower than that of the welded connection. At the later stage of loading, slippage occurs at the end-plate connection of the link, which affects the cumulative energy dissipation capacity of the structure.

3.6. Equivalent Viscous Damping Coefficients. The equivalent viscous damping coefficient $h_{e}$ of the frame can evaluate its ability to absorb and dissipate energy under cyclic loads more reasonably. The equivalent viscous damping coefficient can be calculated by the method shown in Figure 23 and formula (6). The equivalent viscous damping coefficients of the joints are shown in Table 13. 


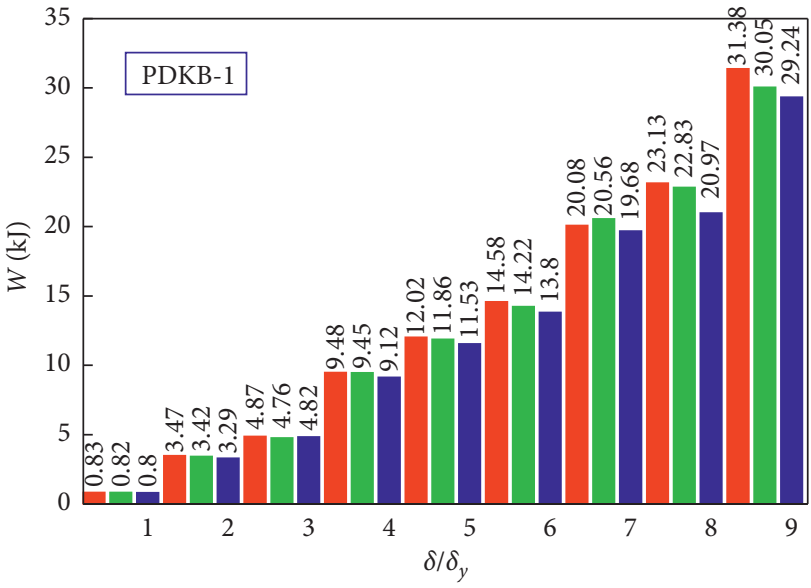

(a)

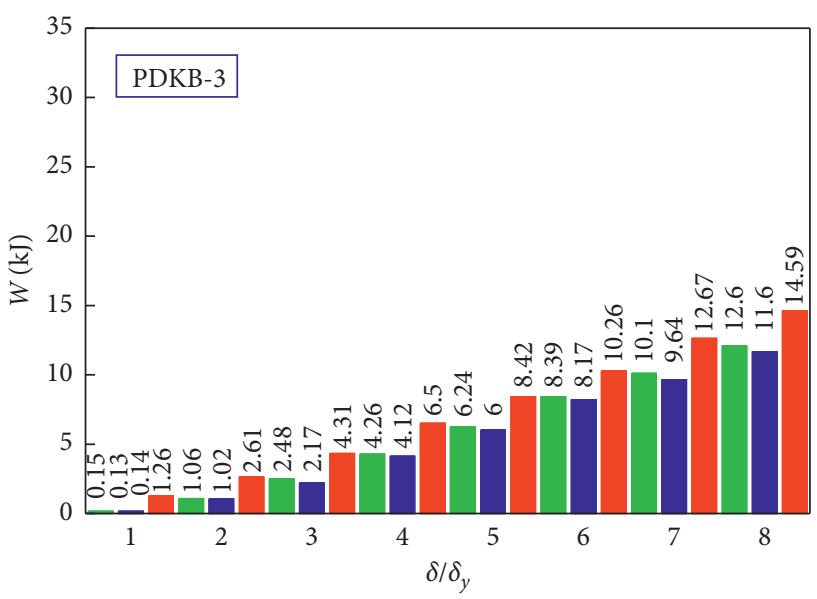

(c)

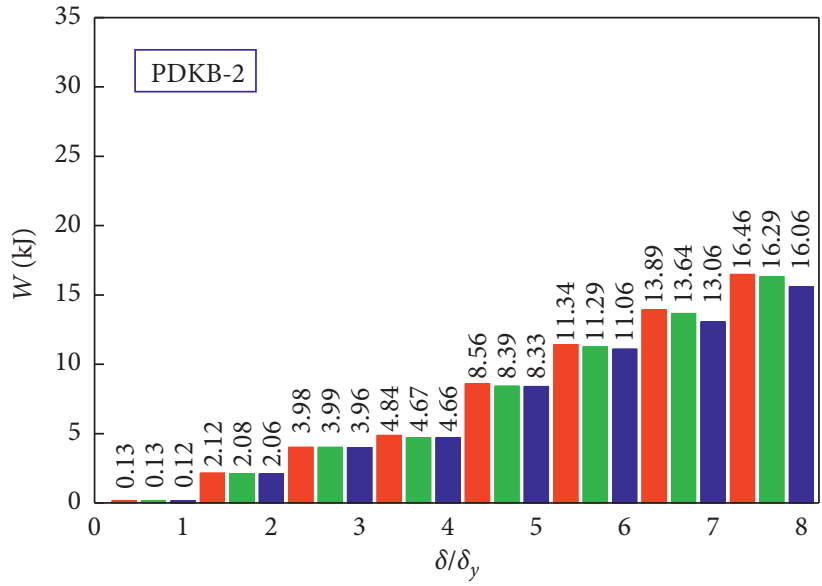

(b)

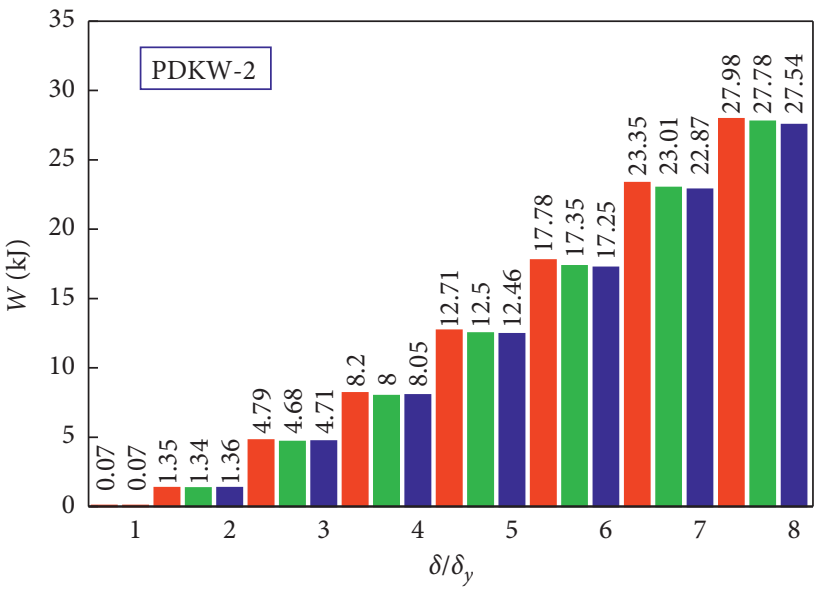

(d)

Figure 22: Energy dissipation of the hysteretic loop in test specimens.

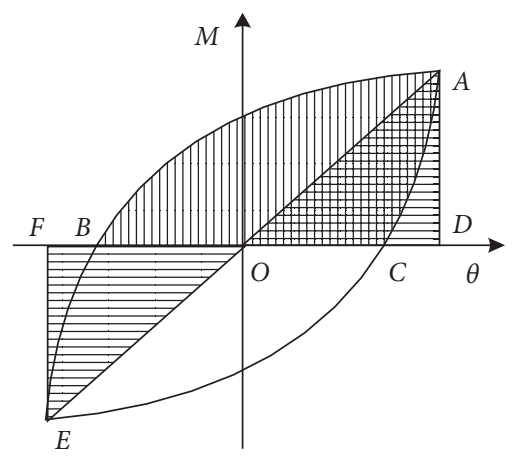

Figure 23: Computing model for equivalent viscous damping coefficient.

$$
h_{e}=\frac{1}{2 \pi} \frac{S_{A B C}+S_{E B C}}{S_{A O D}+S_{E O F}} .
$$

According to Table 13, the equivalent viscous damping coefficients of eccentrically braced semirigid steel frame specimens are analyzed and the following conclusions are drawn. The equivalent viscous damping coefficients of semirigidly braced EBFs are 19\% higher than those of rigidly braced EBFs. With the increase of the link length, the equivalent viscous damping coefficients decrease. PDKB-2 is $18.6 \%$ lower than PDKB-1, and PDKB-3 is 24.9\% lower than PDKB-2. It shows that EBFs with short links have stronger ability to absorb and dissipate seismic energy. 
TABLE 13: Equivalent damping coefficients of the specimens.

\begin{tabular}{lccccccccc}
\hline Specimens & $\delta_{y}$ & $2 \delta_{y}$ & $3 \delta_{y}$ & $4 \delta_{y}$ & $5 \delta_{y}$ & $6 \delta_{y}$ & $7 \delta_{y}$ & $8 \delta_{y}$ & $9 \delta_{y}$ \\
\hline PDKB-1 & 0.1453 & 0.2182 & 0.1875 & 0.1962 & 0.1752 & 0.1721 & 0.1757 & 0.1728 & 0.2121 \\
PDKB-2 & 0.0469 & 0.1879 & 0.2029 & 0.1798 & 0.2006 & 0.2082 & 0.1835 & 0.1726 & - \\
PDKB-3 & 0.0349 & 0.0963 & 0.1151 & 0.1255 & 0.1378 & 0.1368 & 0.1296 & 0.1296 & - \\
PDKW-2 & 0.0545 & 0.0969 & 0.10191 & 0.1151 & 0.1242 & 0.1362 & 0.1439 & 0.1450 & - \\
\hline
\end{tabular}

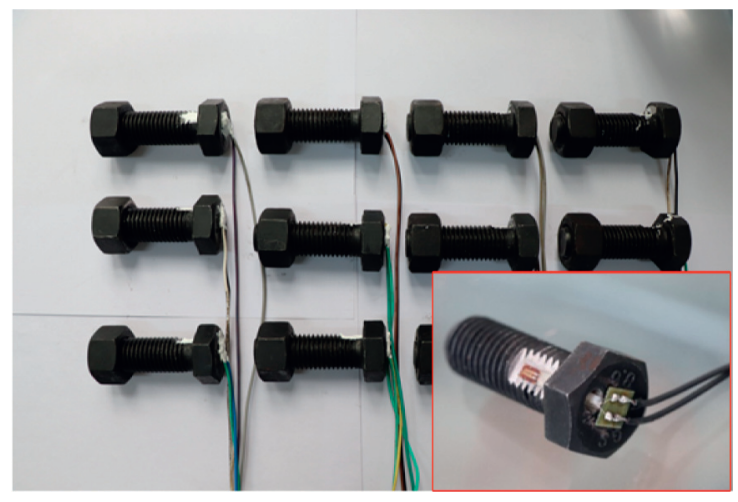

Figure 24: Strain gauge affixed to bolts.

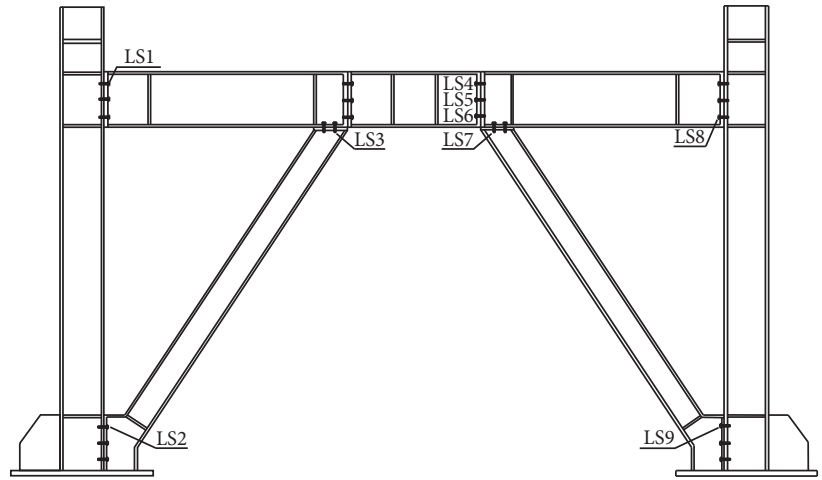

FIgURE 25: Number of bolts in specimens.

3.7. Strain Analysis of Bolts. In order to study the stress characteristics of high-strength bolts in semirigid EBFs, nine high-strength bolts with electronic strain gauges were arranged in each specimen. Before the specimens are installed, the high-strength bolts are milled and the surface is treated. Then the electronic strain gauges are pasted on the bolts. The lead-out wires are pierced through the holes and connected to the strain acquisition instrument. Finally, the holes are sealed with epoxy resin. The bolts with the electronic strain gauges are shown in Figure 24, and Figure 25 shows the numbering diagram of the bolts.

Figure 26 shows the variation of strain of bolts of specimen PDKB-1 with loading displacement. Figure 26(a) shows the bolts at the connection between the link and the end plate of the beam, numbered LS-4, LS-5, and LS-6, respectively. The strain of bolt LS- 4 is the largest among all bolts, and the maximum strain is $8655 \mu \varepsilon$. When the link is subjected to large shear force, the end plate of the link undergoes obvious bending deformation, and bolt LS-4 is subjected to the combined action of tension and shear. Figure 26(b) shows the bolts at the connection between the flange of the beam and the end plate of the brace, numbered LS-3 and LS-7, respectively. The maximum strain of bolt LS7 is $6252 \mu \varepsilon$, and this bolt is in a larger prying force. Figures 26(c) and 26(d) are bolts at the connections between beam end plate and column flange and between brace end plate and column flange, numbered LS-1, LS-8, LS-2, and LS9, respectively. The strain of bolts at beam-to-column connection and in beam-to-brace connection is at a low level. The maximum strain of LS-1 is $743 \mu \varepsilon$, and the minimum strain of LS-9 is $-814 \mu \varepsilon$.

Figure 27 shows the experimental phenomena at bolt holes observed after the failure of the specimens. The screw marks of bolt hole wall of end plate of link are obvious. Bolt hole of LS-4 has elliptical characteristics.

Figures 28 and 29 are the variation of strain of bolts for specimens PDKB-2 and PDKB-3 with loading displacement, respectively. The variation trend of strain in bolts with loading displacement is similar to that of specimen PDKB-1. 


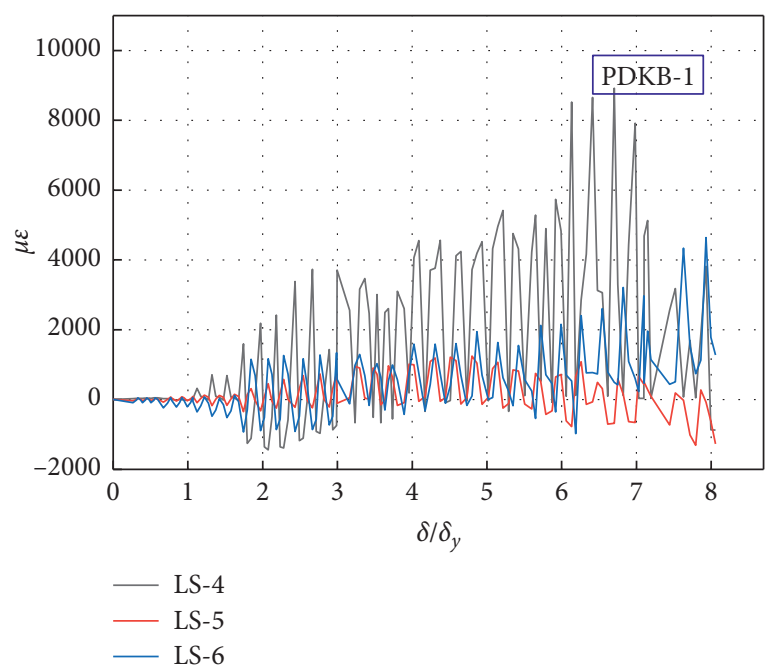

(a)

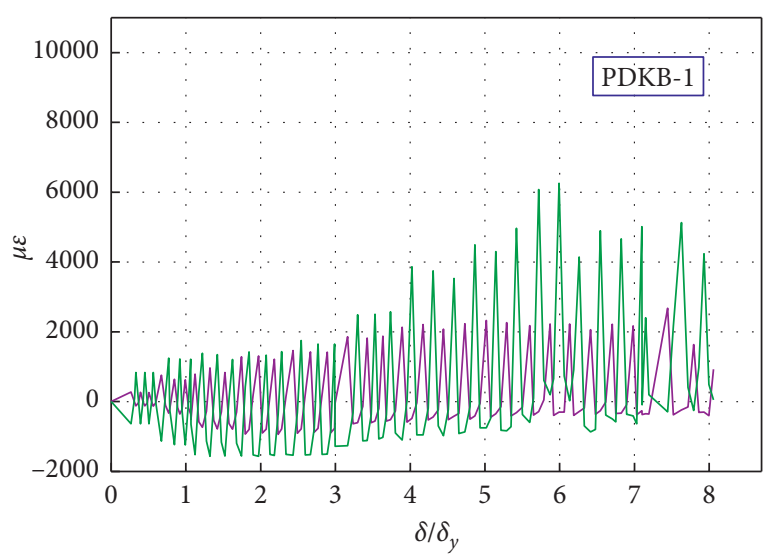

LS-3
- LS-7

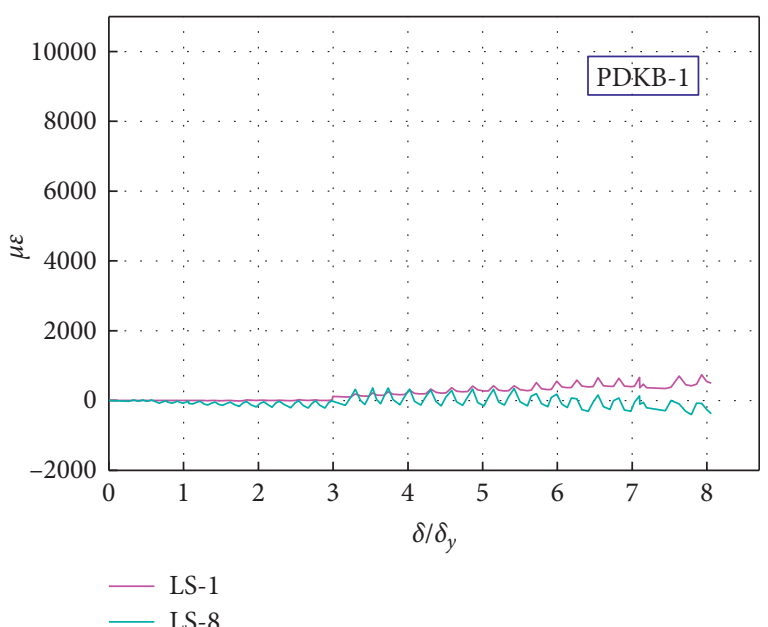

(b)

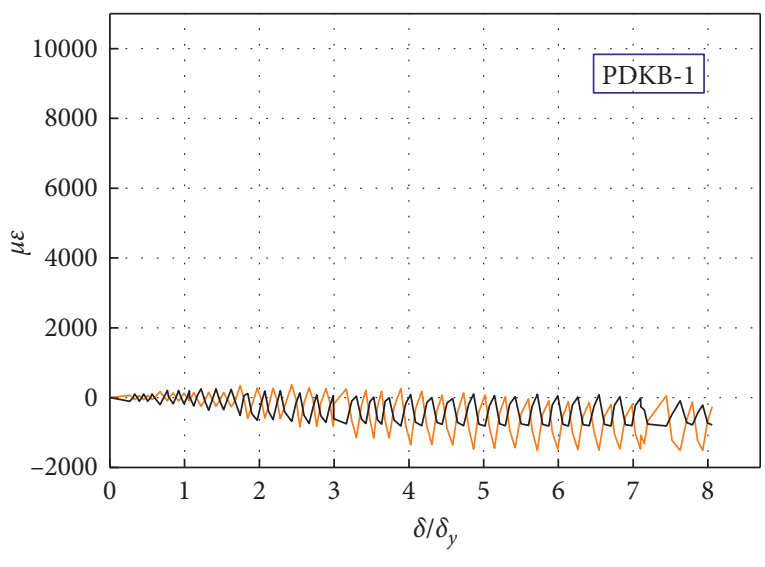

— LS-2

(c)

(d)

FIgURE 26: Strain of bolts in specimen PDKB-1.
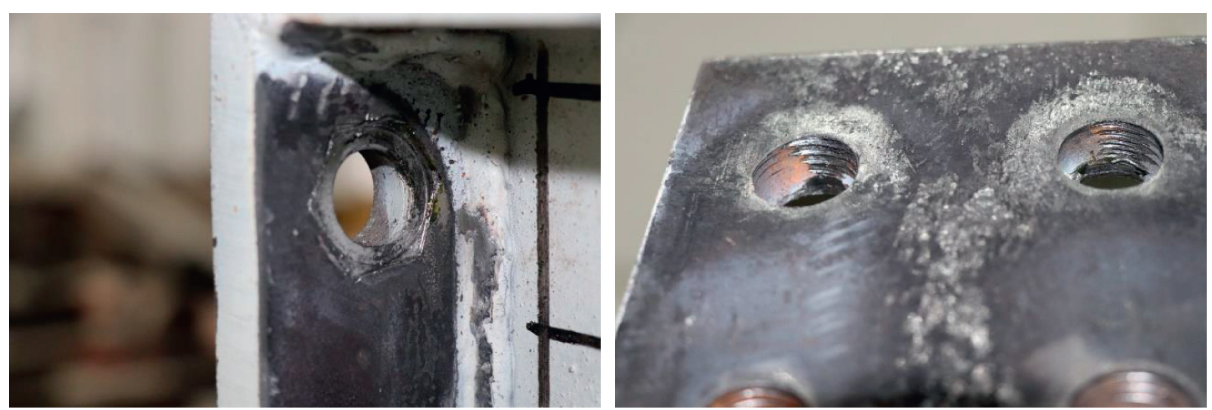

FIgURE 27: Deformation at bolts hole.

Table 14 shows the maximum strain of bolts in the whole loading history, which includes the strain value 1400 $\mu \varepsilon$ of bolts after prestressing. The analysis shows that the strain of bolts at beam-to-column connections (LS-1 and LS-8) is the smallest, followed by the strain of bolts at column-foot connections (LS-2 and LS-9); the strain of bolts at brace-to-beam connections (LS-3 and LS-7) is larger, and the strain of bolts at link-to-beam connections (LS-4, LS-5, and LS-6) is the largest, and the maximum strain is $11343 \mu \varepsilon$. 


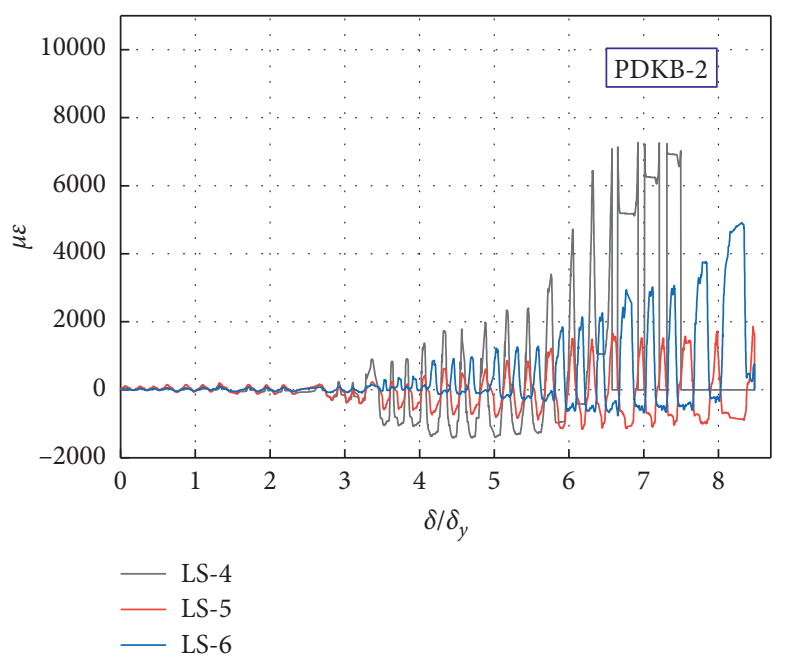

(a)

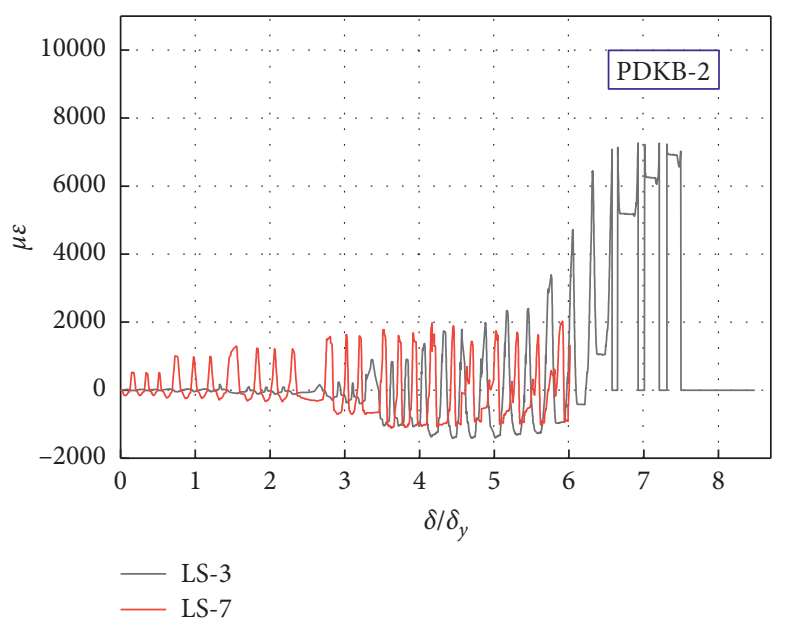

(c)

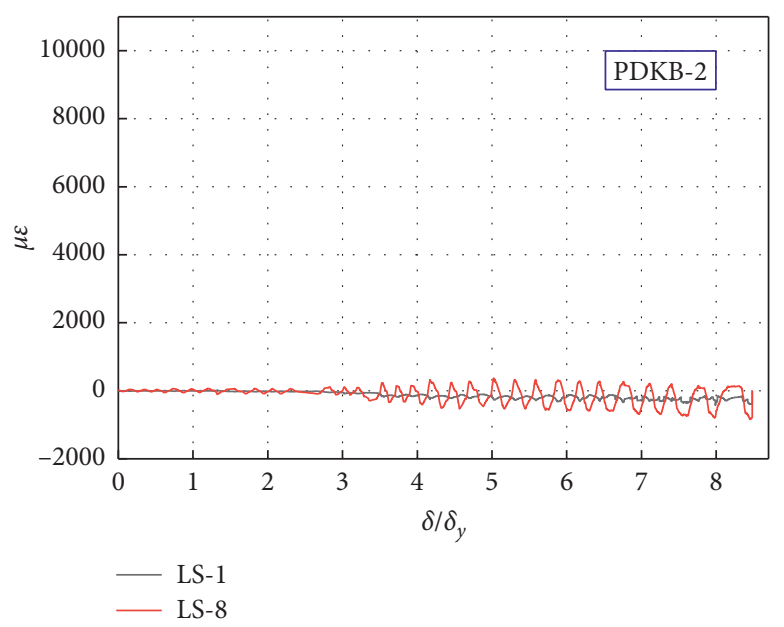

(b)

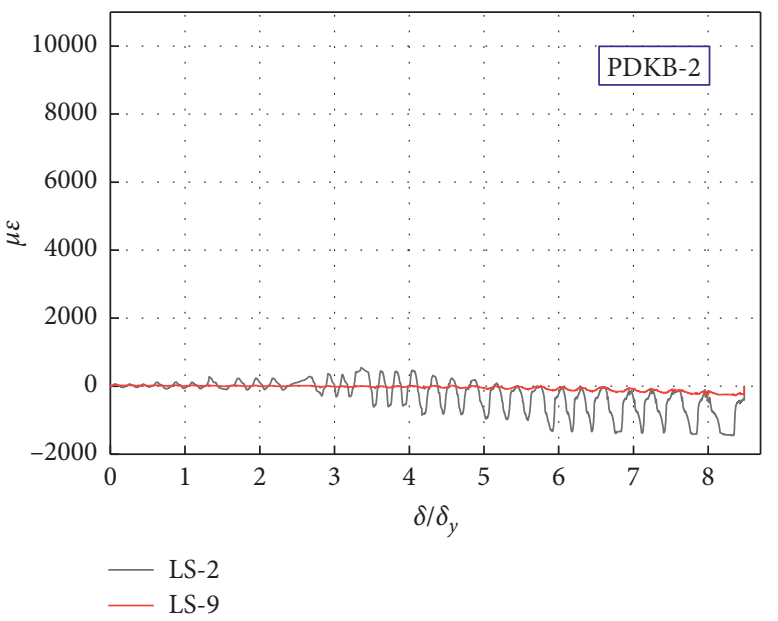

(d)

Figure 28: Strain of bolts of specimen PDKB-2.

\section{FEM Simulations}

Based on quasi-static test research of EBFs with semirigid connections, the rationality of the finite element analysis was first verified by comparison with the test results and then nonlinear finite element analysis was performed using 7 models. Based on these results, the length of the link, the thickness of the end plate, and the column axial force were used as parameters to analyze their influences on the hysteretic performance of the EBFs with semirigid connections. The detailed information of the finite element model is shown in Table 15. To verify the reliability of the finite element analysis, the geometric dimensions of the KEBF-2 are the same as the test specimen PDKB-2.

4.1. Finite Element Analyses (FEA). The simulation is conducted using ABAQUS software (SIMULIA, 2016), and a C3D8R solid element is used, which reduces integration and eight nodes with three degrees of freedom per node [42]. The numerical model is shown in Figure 30.
The material parameters of the FEA model are derived from the material property test. The material of beam, column, and brace is Q345B, and that of the link is Q235B. The steel elastic modulus $(E)$ used is equal to $206 \mathrm{Gpa}$, and the Poisson coefficient $(\nu)$ is equal to 0.3 for all types of materials. The high-strength steel bolt (M22) used is of grade 10.9 (including the bolt heads, shanks, and nuts). According to the stress-strain relationship of the material property test, the measured engineering stress-strain relationship is converted into the real stress-strain relationship according to formulas (9) and (10) [42, 43]:

$$
\begin{aligned}
& \sigma_{\text {true }}=\sigma_{\text {nom }}\left(\varepsilon_{\text {nom }}+1\right), \\
& \varepsilon_{\text {true }}=\ln \left(1+\varepsilon_{\text {nom }}\right),
\end{aligned}
$$

where $\sigma_{\text {nom }}$ is the nominal stress, $\varepsilon_{\text {nom }}$ is the nominal strain, $\sigma_{\text {true }}$ is the true stress, and $\sigma \varepsilon_{\text {true }}$ is the true strain.

The true strain obtained by equation (10) can be divided into two parts, where one is the elastic strain and the other is the plastic strain. When the material is set in 


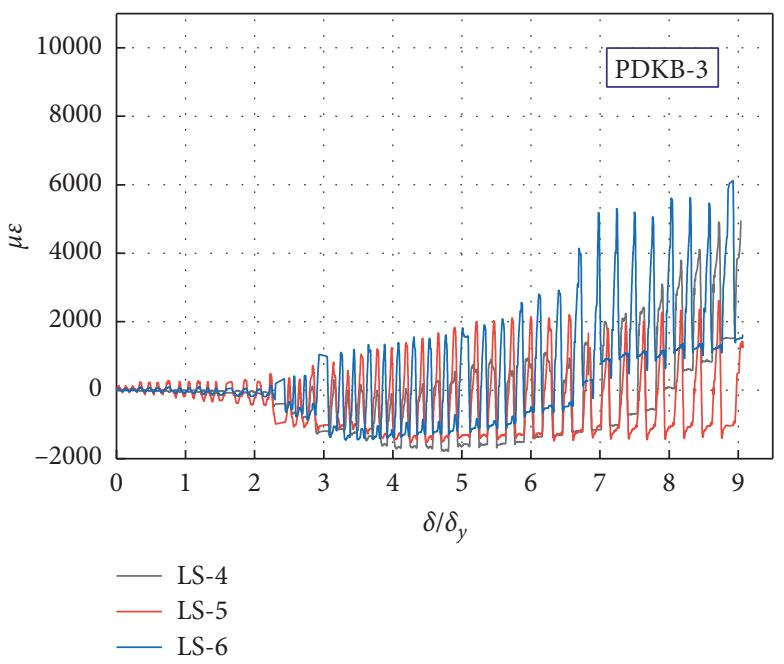

(a)

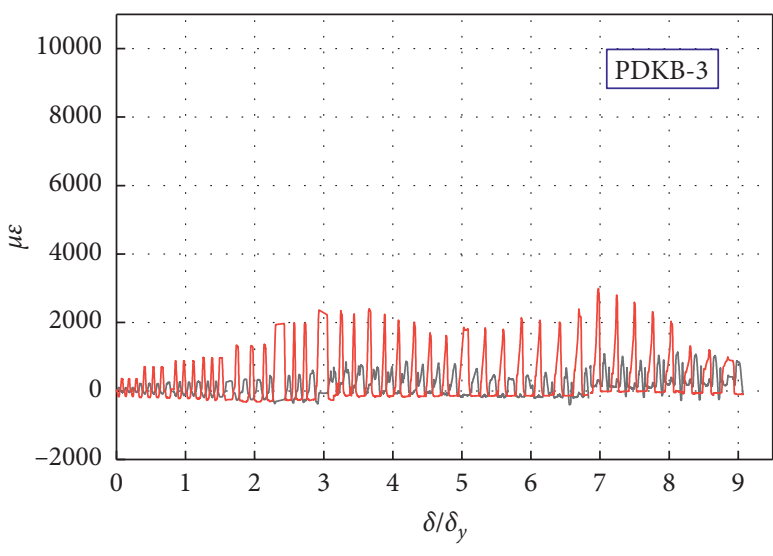

- LS-3

- LS-7

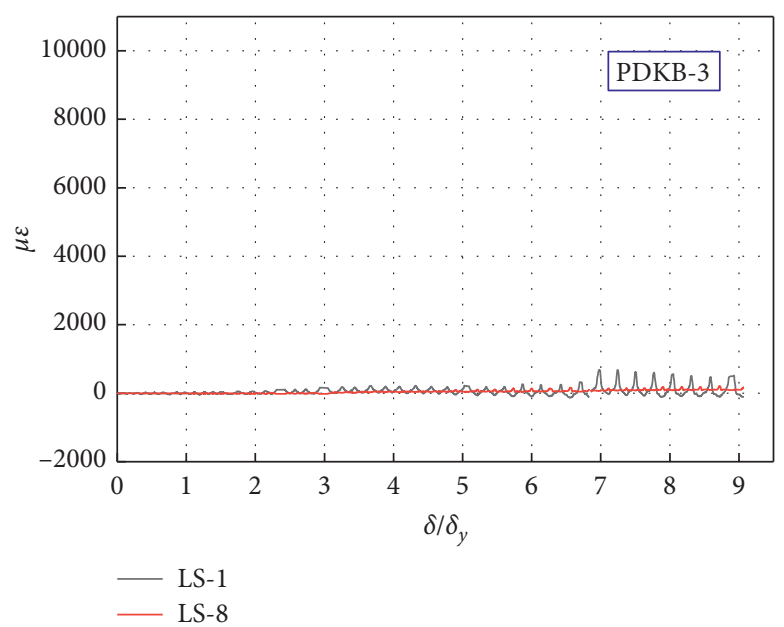

(b)

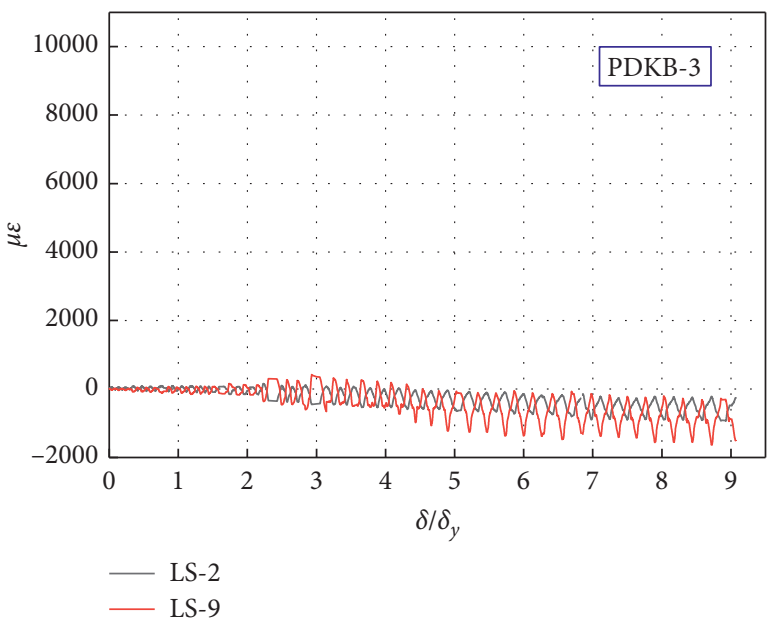

(d)

Figure 29: Strain of bolts of specimen PDKB-3.

TABle 14: Maximum strain of bolts.

\begin{tabular}{llllllllll}
\hline Specimens & LS-1 & LS-2 & LS-3 & LS-4 & LS-5 & LS-6 & LS-7 & LS-8 & LS-9 \\
\hline PDKB-1 & 2143 & 1766 & 4072 & 10321 & 2647 & 3243 & 7652 & 1764 & 1655 \\
PDKB-2 & 1411 & 1937 & 1553 & 10068 & 3257 & 6311 & 6507 & 1705 & 1431 \\
PDKB-3 & 2086 & 1273 & 2535 & 11343 & 4019 & 7517 & 4390 & 1609 & 1264 \\
\hline
\end{tabular}

TABLE 15: The finite element analysis model information.

\begin{tabular}{lccccc}
\hline Models ID & $\begin{array}{c}\text { The length of } \\
\text { link } e(\mathrm{~mm})\end{array}$ & $\begin{array}{c}\text { The length ratio } \\
\text { of link } \rho(\mathrm{mm})\end{array}$ & $\begin{array}{c}\text { The axial force of } \\
\text { column } F_{n}(\mathrm{kN})\end{array}$ & $\begin{array}{c}\text { The thickness of } \\
\text { end plate } t_{\mathrm{e}}(\mathrm{mm})\end{array}$ & $\begin{array}{c}\text { Experiment/FEM } \\
\text { PDKB-2 }\end{array}$ \\
\hline 600 & 1.6 & 200 & 16 & 16 \\
KEBF-1 & 400 & 1.1 & 200 & 16 & Experiment \\
KEBF-2 & 600 & 1.6 & 200 & 16 & FEM \\
KEBF-3 & 740 & 2.0 & 200 & 16 & FEM \\
KEBF-4 & 890 & 2.4 & 200 & 24 & FEM \\
KEBF-5 & 960 & 2.6 & 200 & 16 & FEM \\
KEBF-6 & 600 & 1.6 & 400 & & FEM \\
KEBF-7 & 600 & 1.6 & & FEM \\
\hline
\end{tabular}




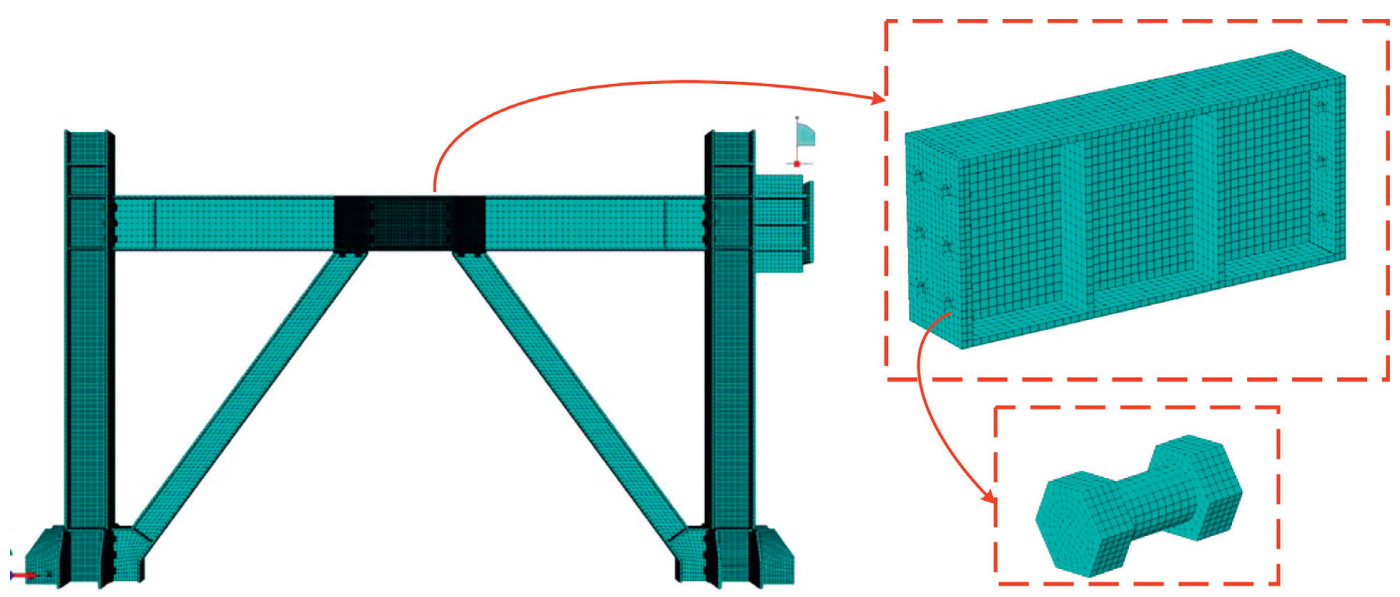

Figure 30: FEA model.

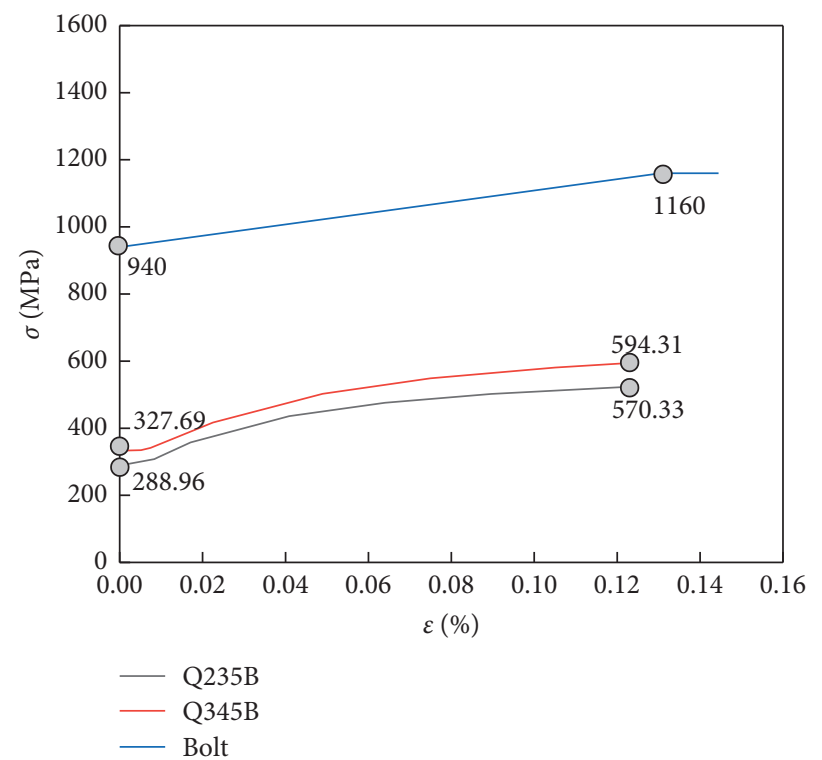

Figure 31: Stress-strain curves for different materials.

ABAQUS, the parameters of the material are defined by the true stress and the plastic strain in the plastic phase. The correlation between true strain and plastic strain is presented as follows:

$$
\varepsilon_{p l}=\varepsilon_{\text {true }}-\varepsilon_{e l}=\varepsilon_{\text {true }}-\frac{\sigma_{\text {true }}}{E},
$$

where $\varepsilon_{p l}$ is the plastic strain and $\varepsilon_{e l}$ is the elastic strain.

Thus, the curve shape of the materials used and the chosen characterization parameters of the multilinear curve are shown in Figure 31.

\subsection{Comparison of the Results from FEA and Experiments.} The comparison of the equivalent stress of KEBF-2 and the failure mode of the link is shown in Figure 32. Comparison of the failure mode of the FEA model and the test specimen is also shown in Figure 32. The figure illustrates the failure that occurred at the flange of the link and the end plate weld which are numerically and experimentally close. It can be concluded that the finite element analysis is reliable.

Comparisons of hysteresis curves and skeleton curves of specimen PDKB-2 by experiment and model KEBF-2 by FEM are shown in Figure 33. The finite element analysis can reflect the hysteresis characteristics that are generally consistent with the test. There are also differences, mainly due to factors such as test installation, or simplifications introduced in the numerical modeling.

Comparisons of capacity and ductility by experiment and by FEM are shown in Table 16. The ultimate bearing capacity of the KEBF-2 model is on average $8.6 \%$ higher than that of the PDKB-2 test piece. It is mainly because the boundary conditions and geometric models in the finite element simulation are ideal models, and there are certain installation deviations, uneven materials, and welding residual stresses during the test. In general, the finite element simulation deviation is within the allowable range. 


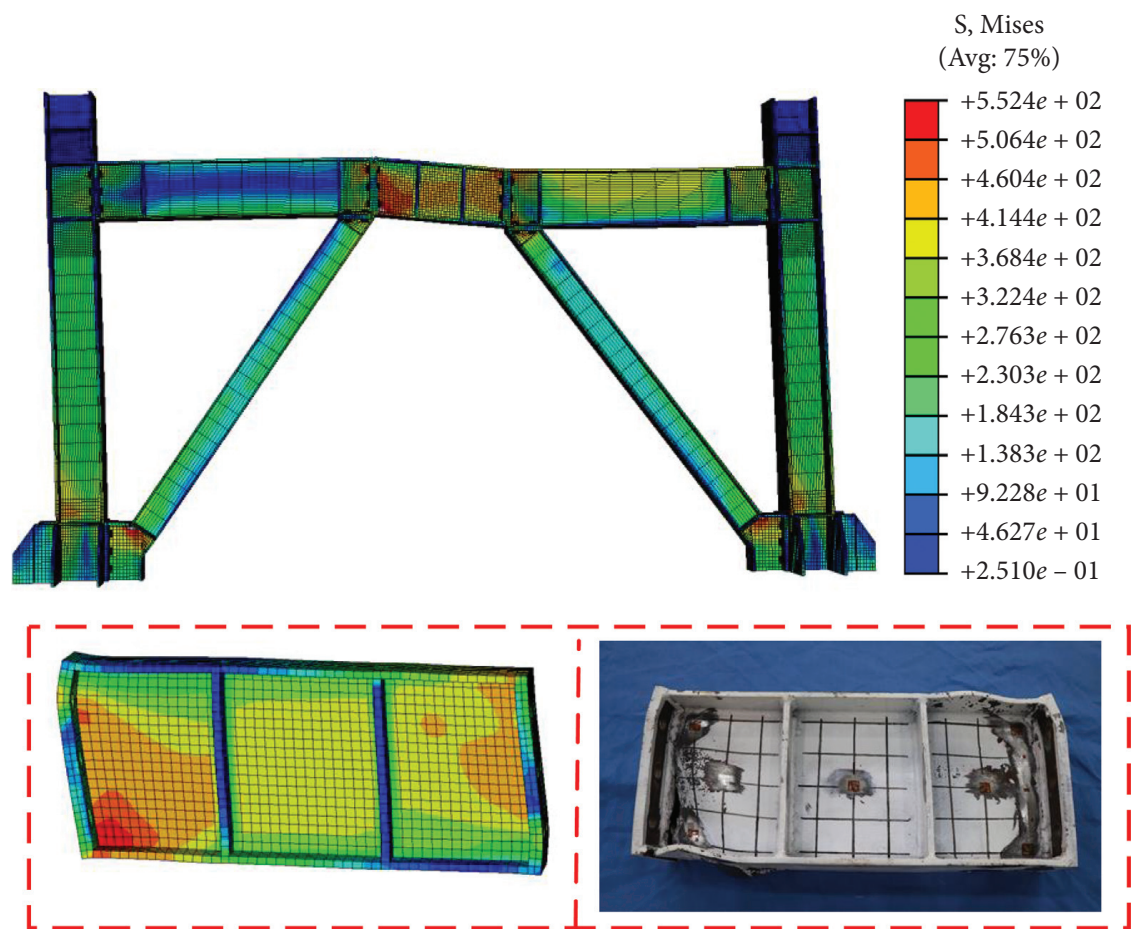

FIgURE 32: Comparison of failure modes and equivalent stress of PDKB-2 and KEBF-2.

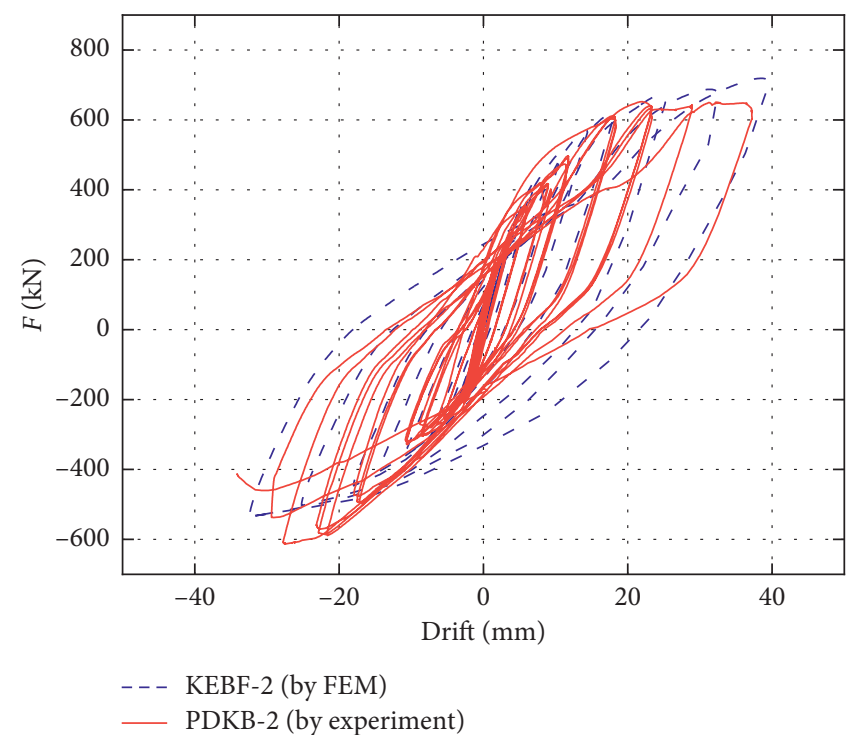

(a)

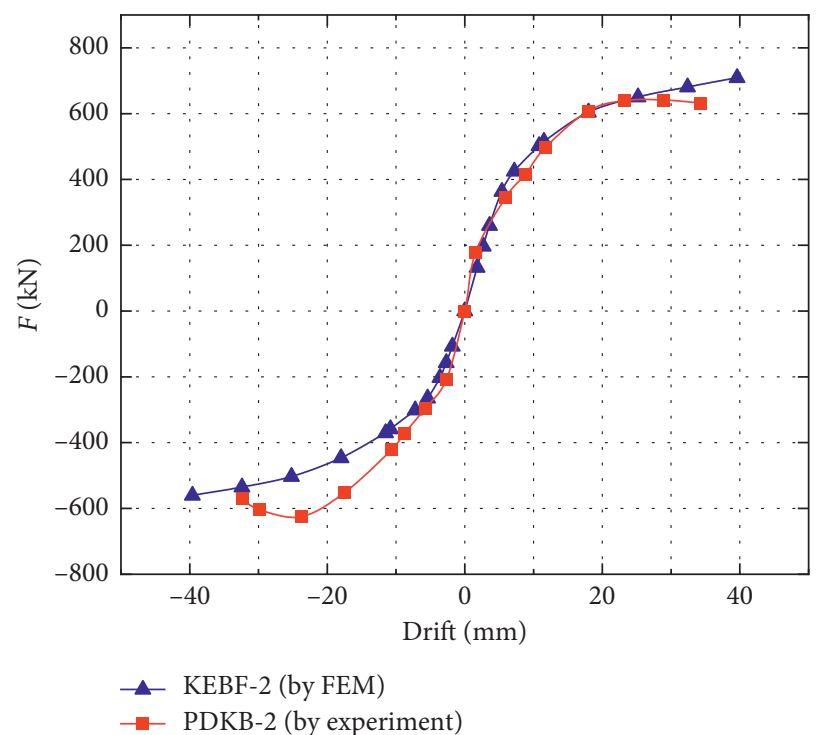

(b)

FIGURE 33: Comparison of hysteresis curves and skeleton curves of PDKB-2 and KEBF-2.

TABLE 16: Comparisons of capacity and ductility by experiment and by FEM.

\begin{tabular}{lcccccc}
\hline \multirow{2}{*}{ Model/specimen } & \multirow{2}{*}{ Load direction } & \multicolumn{2}{c}{ Yield stage } & \multicolumn{2}{c}{ Ultimate stage } & \multicolumn{2}{c}{ Ductility coefficient } \\
& & $\delta_{y}(\mathrm{~mm})$ & $F_{y}(\mathrm{kN})$ & $\delta_{u}(\mathrm{~mm})$ & $F_{y}(\mathrm{kN})$ & $\mu_{\Delta}$ \\
\hline \multirow{2}{*}{ PDKB-2 } & + & 2.37 & 232.78 & 28.88 & 631.78 & 2.83 \\
\multirow{2}{*}{ KEBF-2 } & - & 2.89 & 208.70 & 29.25 & 603.73 & 2.29 \\
& + & 2.70 & 196.77 & 39.60 & 709.26 & 2.61 \\
\hline
\end{tabular}




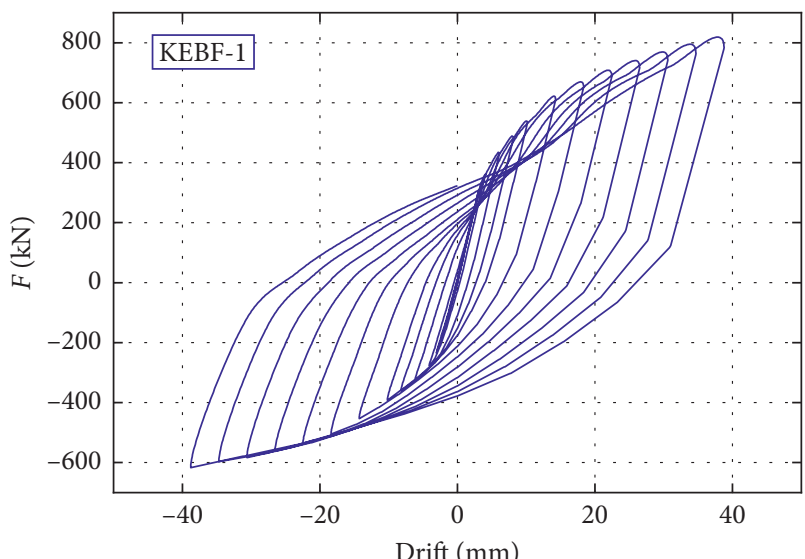

(a)

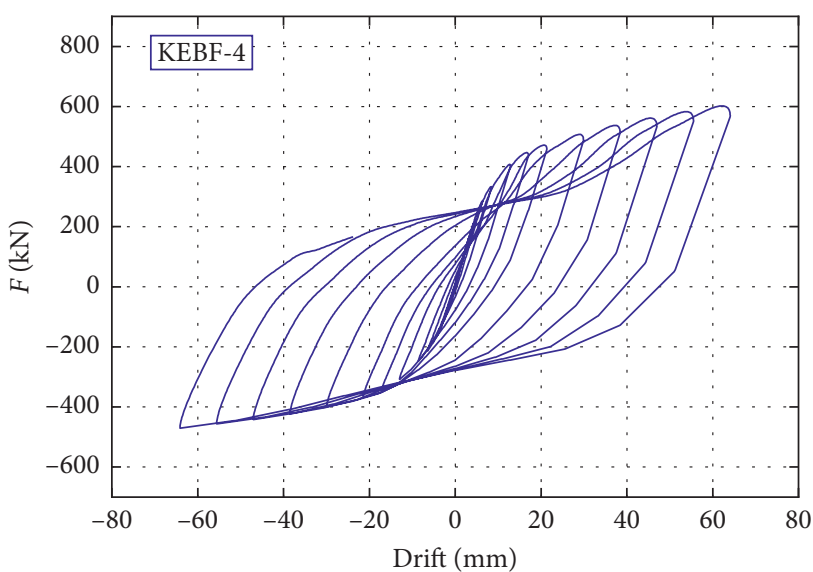

(c)

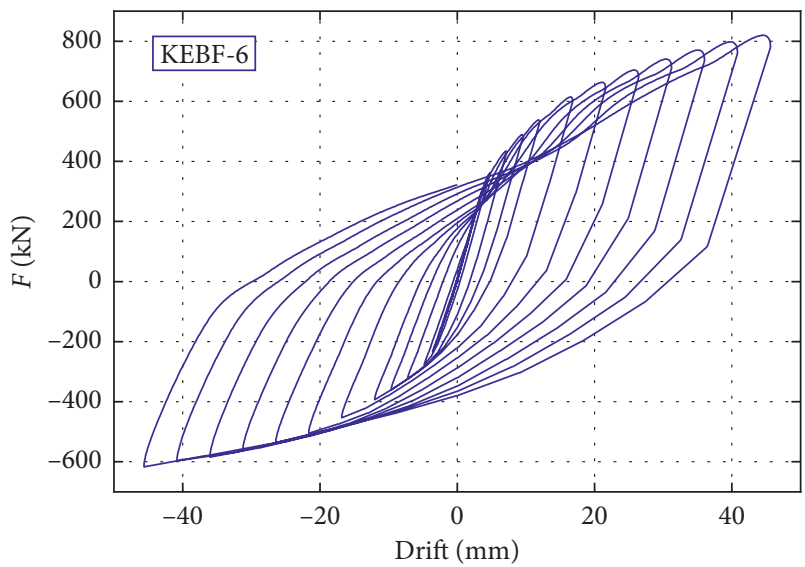

(e)

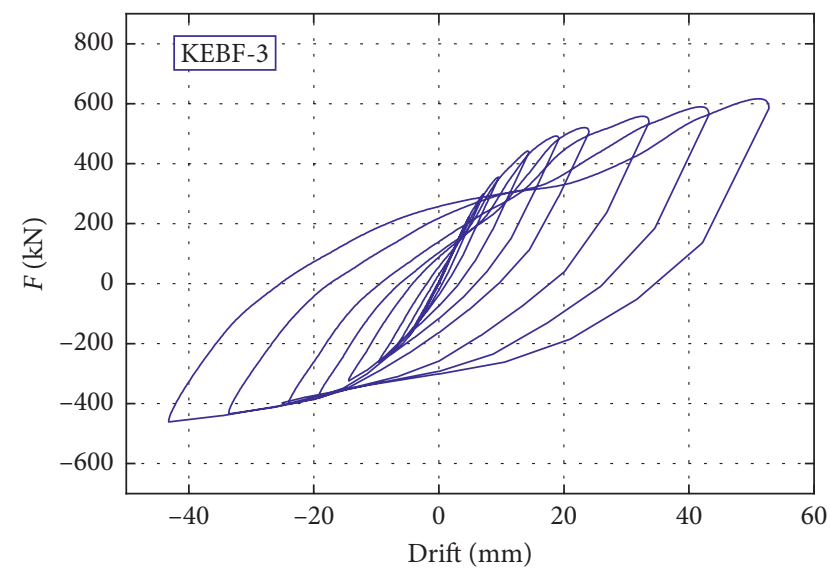

(b)

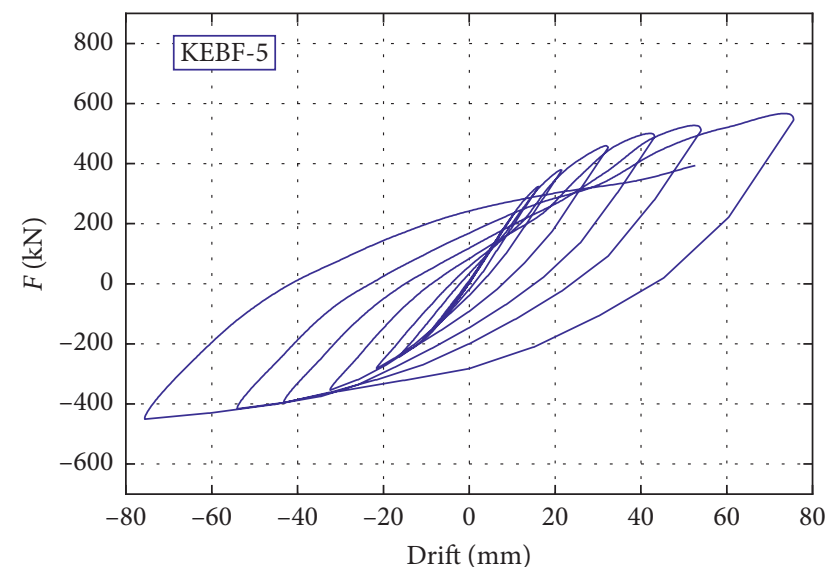

(d)

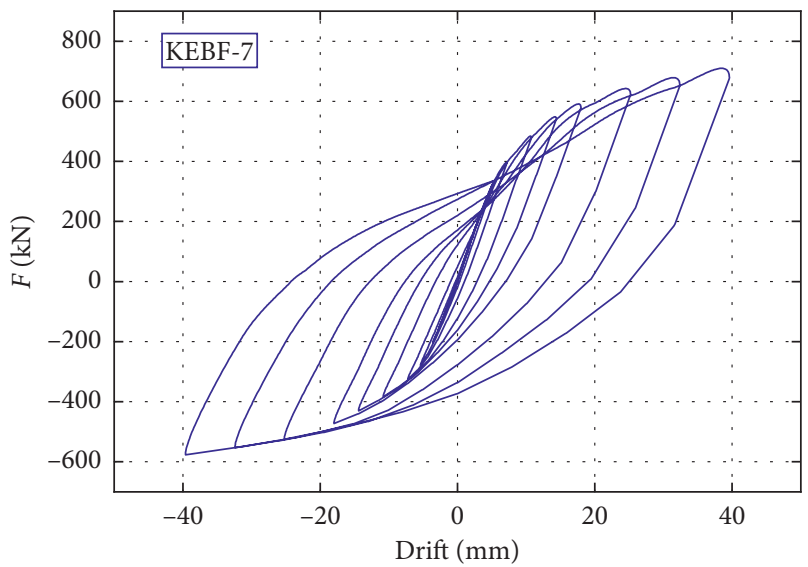

(f)

FIgURE 34: The load-displacement hysteresis curve of each model.

4.3. Results and Discussion of the Parametric Study. Figure 34 is the load-displacement hysteresis curve of each model. The hysteresis curve of KEBF-1 model is relatively full. The length ratio of link of KEBF-1 model is less than 1.6, which is a shear link. The hysteresis curves of all models (from the KEBF-2 to KEBF-5) show different degrees of pinching. It is mainly because the components are bolted, and there is a slip phenomenon during loading. With the increase of the length of the link, the pinching phenomenon increases.
Obviously, this phenomenon is consistent with the experimental results. The hysteresis curve of the KEBF- 6 model is fuller than that of KEBF-2. The main reason is that the thickness of the end plate at the connections of the former model is $24 \mathrm{~mm}$. As the thickness of the end plate increases, the limit displacement of the model increases and the failure delays. The hysteretic performance of EBFs with replaceable links has a greater impact. The hysteresis curve of the KEBF-7 model is generally consistent with that of KEBF-2, indicating 
TABLE 17: Capacity and ductility coefficient of models.

\begin{tabular}{|c|c|c|c|c|c|c|}
\hline \multirow{2}{*}{ Models ID } & \multirow{2}{*}{ Load direction } & \multicolumn{2}{|c|}{ Yield stage } & \multicolumn{2}{|c|}{ Ultimate stage } & \multirow{2}{*}{$\begin{array}{c}\text { Ductility coefficient } \\
\mu_{\Delta}\end{array}$} \\
\hline & & $\delta_{y}(\mathrm{~mm})$ & $F_{y}(\mathrm{kN})$ & $\delta_{u}(\mathrm{~mm})$ & $F_{y}(\mathrm{kN})$ & \\
\hline \multirow{2}{*}{ KEBF-1 } & + & 2.04 & 203.37 & 38.76 & 783.88 & 2.75 \\
\hline & - & 2.04 & 164.64 & 38.76 & 617.16 & 3.08 \\
\hline \multirow{2}{*}{ KEBF-2 } & + & 2.70 & 196.77 & 39.60 & 709.26 & 2.61 \\
\hline & - & 2.70 & 157.45 & 39.60 & 560.58 & 2.11 \\
\hline \multirow{2}{*}{ KEBF-3 } & + & 2.40 & 114.24 & 52.80 & 586.52 & 2.58 \\
\hline & - & 2.40 & 93.96 & 43.20 & 460.91 & 2.29 \\
\hline \multirow{2}{*}{ KEBF-4 } & + & 3.20 & 160.90 & 64.08 & 568.84 & 3.32 \\
\hline & - & 3.20 & 130.71 & 64.08 & 470.49 & 2.95 \\
\hline \multirow{2}{*}{ KEBF-5 } & + & 5.40 & 124.14 & 75.60 & 545.94 & 2.33 \\
\hline & - & 5.40 & 103.32 & 75.60 & 450.37 & 2.13 \\
\hline \multirow{2}{*}{ KEBF-6 } & + & 2.70 & 123.99 & 45.60 & 782.06 & 2.85 \\
\hline & - & 2.70 & 106.96 & 45.60 & 617.06 & 2.49 \\
\hline \multirow{2}{*}{ KEBF-7 } & + & 2.40 & 204.47 & 39.60 & 679.34 & 2.81 \\
\hline & - & 2.40 & 164.44 & 39.60 & 577.13 & 2.34 \\
\hline
\end{tabular}

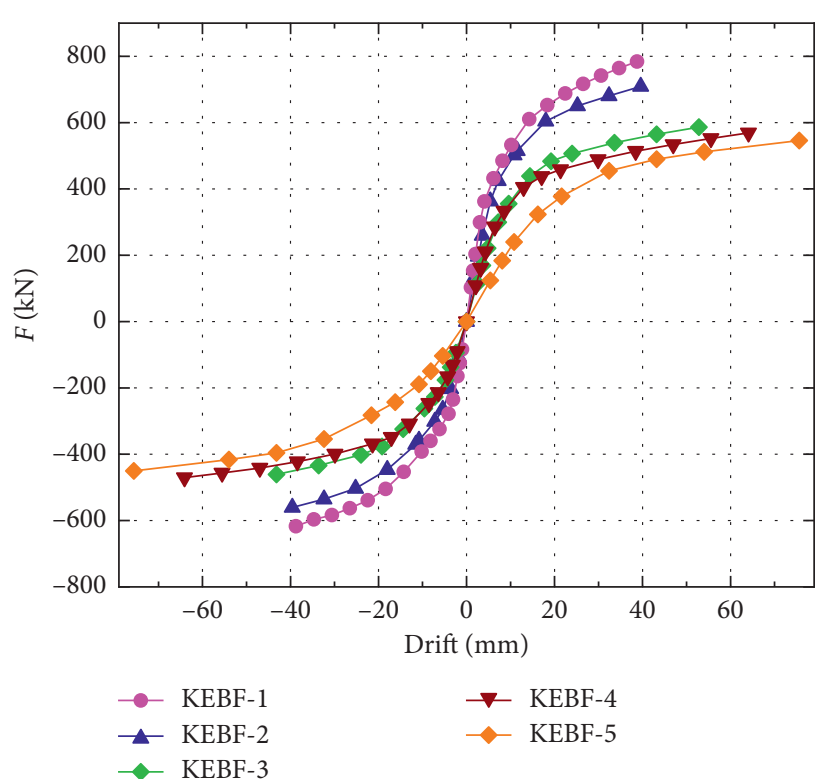

(a)

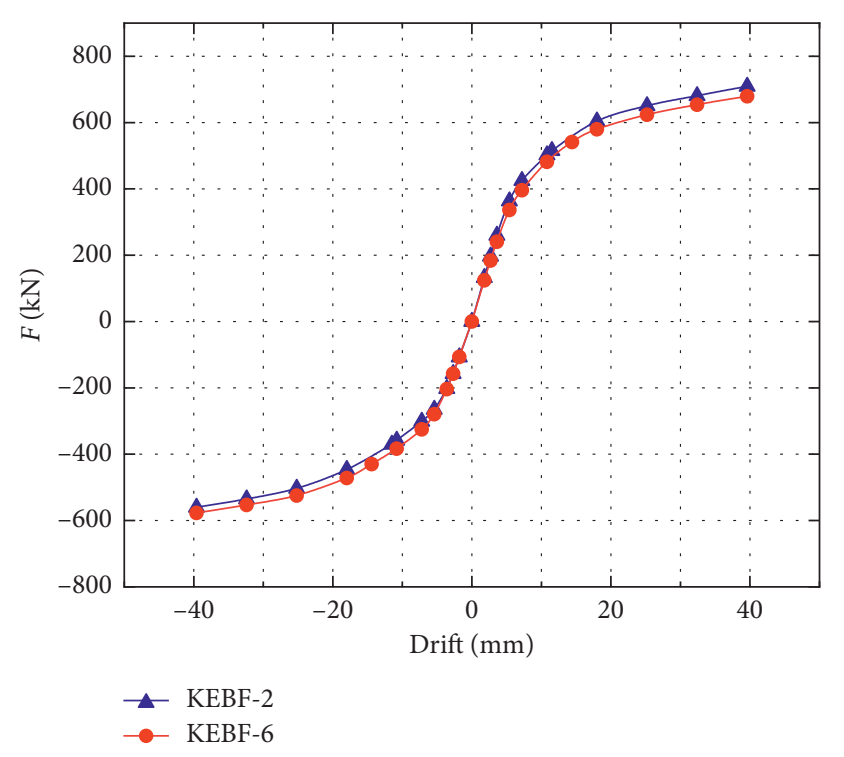

(b)

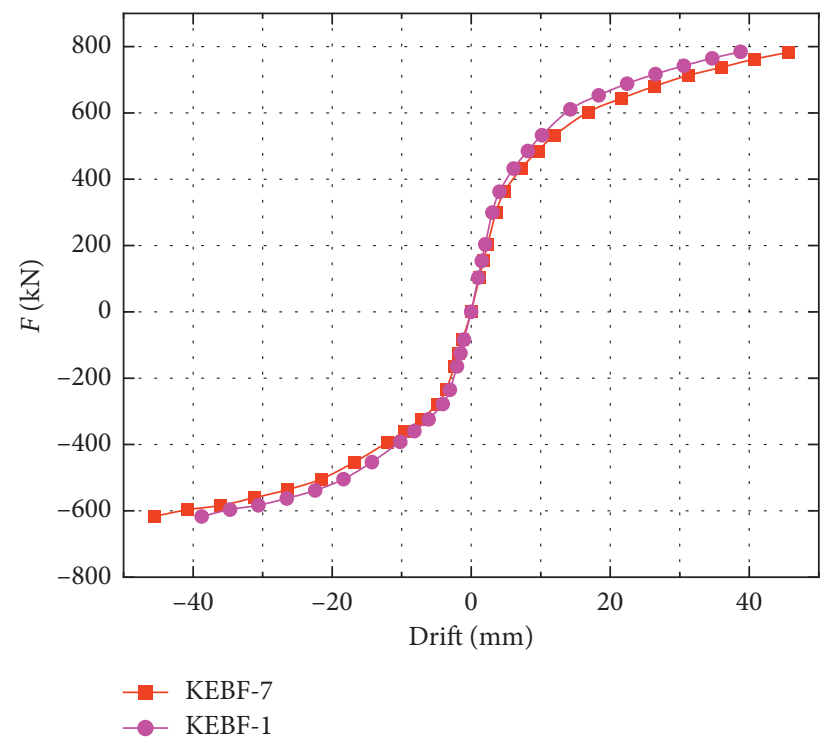

(c)

FIGURE 35: Skeleton curve of each model. 


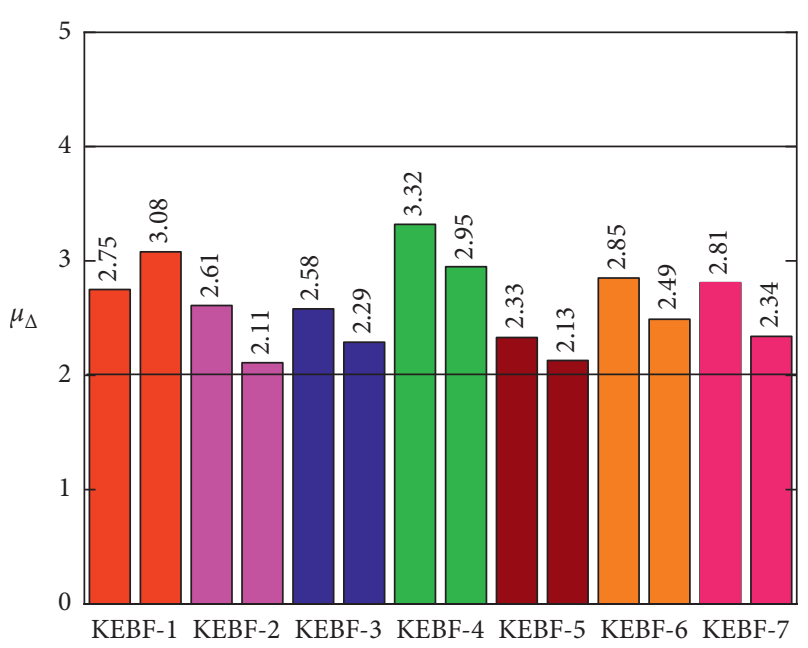

Figure 36: Ductility coefficient of each model.

that the influence of column axial pressure on the hysteretic performance of the structure is limited. In combination with experiments, as can be seen, the welded link shows wider and more stable hysteresis loops if compared with the bolted links. The hysteretic curves of these models are not symmetrical, mainly because the applied load is at the connection between the right column and the beam. When pushing, the out-ofplane stability of the frame is poor. When pulled, the out-ofplane stability of the frame is better.

Table 17 presents the yield displacement, ultimate displacement, yield load, and ultimate load of each model, and Figure 35 shows a skeleton curve of each model. The analysis shows that the ultimate displacement of the frame model increases with the increase of the links length ratio, but the ultimate load decreases. This shows that the bearing capacity of short energy-consuming beams is higher than that of intermediate links (Figure 35(a)). Compared with the KEBF2 model, the KEBF- 6 model has an average ultimate bearing capacity that is $15.15 \%$ higher and an average ultimate displacement that is $10.18 \%$ higher, indicating that the endplate thickness has a significant effect on the ultimate bearing capacity of the model (Figure 35(b)). The ultimate bearing capacity of the KEBF-7 model is $1.06 \%$ lower than that of the KEBF-2 model, indicating that the column axial force has a small effect on the ultimate bearing capacity of the model (Figure 35(c)).

Figure 36 shows the ductility coefficients of each model. The analysis shows that the ductility coefficients of the EBFs with semirigid connections models are between 2 and 4, which indicates that the structure has good ductility. The ductility coefficient is higher when pushing $(+)$ than when pulling $(-)$, with an average of $13.46 \%$.

\section{Conclusions}

In this paper, the hysteretic behavior, bearing capacity, rigidity degradation, ductility, cumulative energy dissipation, and equivalent viscous damping coefficient of the EBFs with semirigid connections are studied by quasi-static test. At the same time, the cooperative working mechanism and failure mechanism of frame with semirigid connections and eccentric brace are observed through experimental phenomena. The following conclusions are drawn.

The failure modes of the EBFs with semirigid connections are the fracture of links end-plate weld or web, and no obvious buckling deformation and cracks occur in the other components. It is easy to be repaired after the earthquake and cost-effective. The bolt joints are used among all the members, which reduces the welding procedure in the construction site and is more efficient.

The length of link is one of the important factors affecting the seismic performance of EBFs with semirigid connections. With the increase of the length ratio of the link, the ultimate load, cumulative energy dissipation, and equivalent viscous damping coefficient all show a downward trend. Short link has better seismic performance than medium-length link. The inelastic rotation of the links of EBFs with bolted joints meets the requirements of 2005 AISC specification. When $\rho$ is $1.0, \gamma$ is $104 \mathrm{mrad}$, which exceeds the limit of $80 \mathrm{mrad}$ in the specification. When $\rho$ is 1.6 and $2.1, \gamma$ is $75 \mathrm{mrad}$ and $65 \mathrm{mrad}$, exceeding the limit of $20 \mathrm{mrad}$. This structure has good plastic inelastic ability.

The welded link shows wider and more stable hysteresis loops if compared with the bolted links. The hysteretic curves of EBFs with semirigid connections show pinching phenomenon due to the slip between end plates. The pinching phenomenon is more obvious with the increase of the length of link.

The bolt strain of beam-to-column connection and column-to-brace connection is small, and it is the largest at link-to-beam connection. At the same time, by observing the bolt hole wall of the specimen, it is found that the bolt thread trace is deepest and the stress state is complex, which should be paid more attention in the design. In future research, the influence of end-plate thickness on seismic performance of structures should be considered.

Both experimental and finite element results show that the ductility coefficient of the EBFs with semirigid connections is between 2 and 4, which shows better ductility. The ductility coefficient is higher when pushing than when pulling, with an average of $13.46 \%$.

Numerical studies were performed to analyze the effects of link length, connection stiffness, and force in the direction of the axis of columns on the seismic performance of eccentrically supported rigid frames. The length and connection stiffness of the link have an effect on the hysteretic performance, ultimate bearing capacity, and ductility of the EBFs. The hysteresis curve is pinched regardless of the short or intermediate link. As the length of the link increases, the ultimate bearing capacity decreases, and ductility increases. As the thickness of the end plate increases, the ultimate bearing capacity and ductility of the EBFs increase. The axial force of the column has little effect on the seismic performance of EBFs.

\section{Nomenclature}

$d: \quad$ Depth of the link

e: $\quad$ Link length 
E: $\quad$ Young's modulus

$f_{y}: \quad$ Yield stress

$f_{u}$ : $\quad$ Ultimate tensile strength

$F_{\text {actuator }}$ : Force of the horizontal actuator

$F_{j}: \quad$ Horizontal load on the $j$-class hysteretic loop vertex

$h$ : Story height

$h_{e}: \quad$ Equivalent damping coefficient

$K_{0}: \quad$ Initial rotational stiffness

$K_{j}$ : $\quad$ Rotational stiffness of the frame

L: $\quad$ Bay width

$M_{p}$ : $\quad$ Plastic moment capacity of the link section

$t_{f}: \quad$ Flange thickness of the link

$t_{w}$ : Web thickness of the link

$V_{p}: \quad$ Link plastic shear capacity

$V_{\text {ult }}$ : Maximum shear force of link

$V_{\text {link: }}$ Link shear force

$Z_{\text {beam }}$ : Plastic section modulus of the link

$W: \quad$ Dissipated energy capability

$\rho: \quad$ Link length ratio

$\delta_{y}$ : Lateral displacement of the column end when the frame starts to yield

$\theta_{p}: \quad$ Yield lateral displacement angle of frame

$\theta_{\mathrm{ult}}: \quad$ Maximum lateral displacement angle of frame

$\gamma_{p}: \quad$ Yield angle of link

$\gamma_{\mathrm{ult}}: \quad$ Maximum angle of link

$\varepsilon_{y}: \quad$ Yield strain

$\Delta_{j}$ : The corresponding lateral displacement under the j-class load

$\lambda_{j}: \quad$ Rigidity degradation coefficient

$\mu_{\Delta}: \quad$ Angular displacement ductility coefficient

$\zeta_{e}: \quad$ Equivalent damping coefficient.

\section{Data Availability}

The data used to support the findings of this study are available from the corresponding author upon request.

\section{Conflicts of Interest}

The authors declare that they have no conflicts of interest.

\section{Acknowledgments}

This research was financially supported by the National Natural Science Foundation of China (Grant no. 51678284), Henan Scientific and Technological Innovation Project for Prominent Talents (no. 184200510016), and Science and Technology Department of Henan Province of China (no. 202102310570).

\section{References}

[1] S. Hu, Study of Advanced Analysis and Performance Based Plastic Design for Eccentrically Braced Steel Frames, South China University of Technology, Guangzhou, China, 2014, in Chinese.

[2] Y. Shi, J. Xiong, Y. Wang et al., "Experimental studies on seismic performance of multi-storey steel frame with eccentric brace," Journal of Building Structure, vol. 31, no. 2, pp. 29-34, 2010, in Chinese.

[3] A. Catapano, E. Nastri, and S. Streppone, "Design and analysis of dual EBFs equipped with prequalified connections," in Proceedings of the 7th International Conference on Computational Methods in Structural Dynamics and Earthquake Engineering (COMPDYN 2015), Crete, Greece, June 2019.

[4] American Institute of Steel Construction (AISC), Seismic Provisions for Structural Steel Buildings, ANSI/AISC341-10 AISC, Chicago, IL, USA, 2016.

[5] European Commitee for Standardization, EN 1998-1:2004, Design of Structures for Earthquake Resistance Part 1: General Rules, Seismic Actions and Rules for buildings, European Standard, Comité Européen de Normalisation, Brussels, Belgium, 2004.

[6] GB50017-2010, Code for Seismic Design of Buildings, China Architecture Industry Press, Beijing, China, 2010.

[7] D.A. Nethecrot, "Semi-rigid joint action and the design of non-sway composite frames," Engineer Structure, vol. 17, no. 8, 1995.

[8] N. Kishi and W. F. Chen, "Data base of steel beam-to-column connections," Structural engineering report no. CE-STR-8626, School of Civil Engineering, Purdue University, West Lafayette, IN, USA, 1986.

[9] A. Abolmaali, A. A. Kukreti, and M. Ghassemieh, "Energy dissipation characteristics of semi-rigid connections," Journal of Constructional Steel Research, vol. 65, no. 5, pp. 1187-1197, 2009.

[10] S. ElnashaiA, A. Y. Eldhazouli, and F. A. Denesh-Ashtiani, "Response of semi-rigid steel frames to cyclic and earthquake loads," Journal of Structural Engineering, ASCE, vol. 124, no. 8, pp. 857-867, 1998.

[11] M. Ivanyi and G. Varga, "Large scale tests of steel frames with semi-rigid connections under quasi-static cyclic loadings," in Proceedings of the 3rd International Conference on Behavior of Steel Structure in Seismic Areas STEESSA, Montreal, Canada, August 2000.

[12] J. M. Rides and E. P. Popov, "Inelastic link element for EBF seismic analysis," Journal of Structural Engineering, vol. 120, no. 2, 1994.

[13] S. Kazemzadeh Azad and C. Topkaya, "A review of research on steel eccentrically braced frames," Journal of Constructional Steel Research, vol. 128, pp. 53-73, 2017.

[14] K. Kasai and E. P. Popov, "General behavior of WF steel shear link beams," Journal of Structural Engineering, vol. 112, no. 2, pp. 362-382, 1986.

[15] A. Daneshmand and B. Hosseini Hashemi, "Performance of intermediate and long links in eccentrically braced frames," Journal of Constructional Steel Research, vol. 70, pp. 167-176, 2012.

[16] A. Chesoan, A. Stratan, and D. Dubina, "Design implementation of re-centring dual eccentrically braced frames with removable links," Soil Dynamics and Earthquake Engineering, vol. 112, pp. 174-184, 2018.

[17] M. Zimbru, M. D’Aniello, A. Stratan, R. Landolfo, and D. Dubină, "Finite element analysis of composite replaceable short links," Key Engineering Materials, vol. 763, pp. 576-583, 2018.

[18] A. Ioan, A. Stratan, D. Dubină et al., "Experimental validation of re-centring capability of eccentrically braced frames with removable links," Engineering Structures, vol. 113, pp. 335346, 2016.

[19] A. Ioan, A. Stratan, and D. DubinǍ, "Re-centring dual eccentrically braced frames with removable links," Proceedings 
of the Romanian Academy Series A-Mathematics Physics Technical Sciences Information Science, vol. 17, no. 2, pp. 169-177, 2016.

[20] D. Dubina, A. Stratan, and F. Dinu, "Dual high-strength steel eccentrically braced frames with removable links," Earthquake Engineering \& Structural Dynamics, vol. 37, no. 15, pp. 1703-1720, 2008.

[21] N. Mansour, C. Christopoulos, and R. Tremblay, "Experimental validation of replaceable shear links for eccentrically braced steel frames," Journal of Structural Engineering, vol. 137, no. 10, pp. 1141-1152, 2011.

[22] A. Ashikov, G. C. Clifton, and B. Belev, "Experimental study on eccentrically braced frames with a new type of bolted replaceable active link," in Proceedings of the 6th National Conference on Earthquake Engineering and the 2nd National Conference on Earthquake Engineering and Seismology-6CNIS \& 2CNISS, Bucharest, Romania, June 2017.

[23] J. J. Ramsay, A. Fussell, and R. G. Wilkinson, "Design of replaceable-link eccentric braced frames in post-earthquake christchurch," in Proceedings of the Steel Innovations Conference 2013, Christchurch, New Zealand, February 2013.

[24] M. B. Bozkurt and C. Topkaya, "Replaceable links with direct brace attachments for eccentrically braced frames," Earthquake Engineering \& Structural Dynamics, vol. 46, no. 13, pp. 2121-2139, 2017.

[25] M. B. Bozkurt and C. Topkaya, "Replaceable links with gusseted brace joints for eccentrically braced frames," Soil Dynamics and Earthquake Engineering, vol. 115, pp. 305-318, 2018.

[26] M. B. Bozkurt, S. Kazemzadeh Azad, and C. Topkaya, "Development of detachable replaceable links for eccentrically braced frames," Earthquake Engineering \& Structural Dynamics, vol. 48, no. 10, pp. 1134-1155, 2019.

[27] Canadian Standards Association (CSA), Design of Steel Structures, CAN/CSA-S16, Mississauga, Canada, 2009.

[28] New Zealand Standards 3404, Part 7, Design for Earthquakes, Steel structures Standard, Wellington, New Zealand, 2009.

[29] GB50017-2017, Code for Seismic Design of Buildings, China Architecture Industry Press, Beijing, China, 2017, in Chinese.

[30] E. P. Popov and M. D. Engelhardt, "Seismic eccentrically braced frame," Journal of Constructional Steel Research, vol. 10, pp. 321-354, 1998.

[31] D. N. Manheim and E. P. Popov, "Plastic shear hinges in steel frames," Journal of Structural Engineering, vol. 109, no. 10, pp. 2404-2419, 1983.

[32] J. O. Malley and E. P. Popov, "Shear links in eccentrically braced frames," Journal of Structural Engineering, vol. 110, no. 9, pp. 2275-2295, 1984.

[33] GB/T 288.1-2010, Metallic Materials. Tensile Testing-Part 1: Method of Test at Room Temperature, AQSIQ and SAC, Beijing, China, 2010.

[34] GB 50205-2001, Code for Acceptance of Construction Quality of Steel Structures, MOC, Beijing, China, 2002.

[35] Q. Shi, S. Yan, L. Kong, X. Bu, X. Wang, and H. Sun, "Seismic behavior of semi-rigid steel joints-Major axis T-stub and minor axis end-plate," Journal of Constructional Steel Research, vol. 159, pp. 476-492, 2019.

[36] K. D. Hjelmstd, E. P. Popov, and F. ASCE, "Characteristices of eccentrically braced frames," Jounal of Structural Engineering, vol. 112, no. 2, 1984.

[37] A. Kuşyılmaz and C. Topkaya, "Design overstrength of steel eccentrically braced frames," Journal of Constructional Steel Research, vol. 13, no. 3, pp. 529-545, 2013.
[38] J. Wang, H. Zhang, and Z. Jiang, "Seismic behavior of blind bolted end plate composite joints to CFTST columns," ThinWalled Structures, vol. 108, pp. 256-269, 2016.

[39] JCJ/T101-2015, Specification for Seismic Test of Buildings, MOHURD, Beijing, China, 2015.

[40] Q. Yao and P. Chen, Structure Test of Civil Engineering, China Architecture and Building Press, Beijing, China, 2010.

[41] V. Gomes, A. T. Silva, L. R. O. D. Lima, and P. C. G. D. S. Vellasco, "Numerical investigation of semi-rigid connection ultimate capacity," REM-International Engineering Journal, vol. 71, no. 4, pp. 505-512, 2018.

[42] A. T. Daloglu, M. Artar, and A. İ. Karakas, "Optimum design of braced steel space frames including soil-structure interaction via teaching-learning-based optimization and harmony search algorithms," Advances in Civil Engineering, vol. 2018, Article ID 3854620, 16 pages, 2018.

[43] J. Jiang, C. K. Chiew, and P. L. Y. Tiong, "A numerical study on residual stress of high strength steel box column," Journal of Constructional Steel Research, vol. 128, pp. 440-450, 2017. 